\title{
Influences of residual stresses and initial distortion on springback prediction of 7B04-T651 aluminium plates in creep-age forming
}

\author{
Aaron C.L. Lam ${ }^{\mathrm{a}}$, Zhusheng Shi ${ }^{\mathrm{a}}$, Jianguo Lin ${ }^{\mathrm{a}}$ and Xia Huang ${ }^{\mathrm{b}}$ \\ ${ }^{\mathrm{a}}$ Department of Mechanical Engineering, Imperial College London, London SW7 2AZ, UK \\ ${ }^{\mathrm{b}}$ AVIC Beijing Aeronautical Manufacturing Technology Research Institute, Beijing 100024, PR China
}

*Corresponding author: J. Lin; E-mail: Jianguo.Lin@Imperial.ac.uk

\begin{abstract}
Springback behaviour of surface-machined 7B04-T651 aluminium plates of 3 to 8 $\mathrm{mm}$ thicknesses, creep-age formed under a single curvature bending radius of $1200 \mathrm{~mm}$, has been experimentally investigated. The surface residual stress levels of the plates have been measured and the typical residual stress distribution and values in 7000-series aluminium alloys have been reviewed and analysed. Finite element models have been developed to simulate creep-age forming (CAF) processes and predict the amount of springback in the physical CAF test. Machining-induced residual stresses and distortion have been considered in the finite element models. This paper presents a first attempt to study the effect of machining-induced residual stresses on the errors of springback prediction in CAF of 7000series aluminium alloy panel components. It has been found that the effect of machininginduced residual stresses on the accuracy of springback prediction is related to the initial loading stress levels in CAF. In addition, when the initial distortion conforms to the loading curvature, an opposing effect on the material's deformation is observed.
\end{abstract}

Keywords: Creep-age forming, Machining-induced residual stress, Initial distortion, Aluminium plates, Springback prediction errors 


\section{Nomenclature}

$d$ Depth below a machined plate surface where the maximum level of compressive residual stress is observed.

$d_{r}$ Displacement loading condition applied to the upper workheads of form tool.

$h$ Thickness of plate.

$k_{\varepsilon c} \quad$ Creep-ageing material constant related to effective creep strain rate.

$m_{1}$ Creep-ageing material constant related to rate of age hardening.

$m_{2}$ Creep-ageing material constant related to the depletion of solute into precipitate.

$m_{3}$ Creep-ageing material constant related to rate of precipitate growth.

$m_{4}$ Creep-ageing material constant controlling the effect of dislocation density (or creep) on precipitate nucleation and growth.

$m_{5}$ Creep-ageing material constant related to rate of dislocation density.

$n_{d}$ Creep-ageing material constant related to rate of dislocation hardening.

$r$ Bending radius of forming tool.

$\bar{r}_{p}, \dot{r_{p}} \quad$ Normalised precipitate size and its rate term respectively.

$\bar{r}_{p}^{0} \quad$ Initial value for normalised precipitate size.

$r_{w}$ Radius of revolvement of workheads of the flexible form tool.

$t$ Creep-ageing time.

$t_{1}, t_{2}, t_{3}, t_{4}$ Time of loading, heating, cooling and unloading respectively.

$t_{A A} \quad$ Artificial ageing time.

$t_{S H T}$ Solution heat treatment time.

$u_{x}, u_{y}, u_{z}$ Translational degrees of freedom in Cartesian coordinates.

$u r_{x}, u r_{y}, u r_{z}$ Rotational degrees of freedom in Cartesian coordinates.

$v$ Poisson's ratio.

$x, y, z \quad$ Cartesian coordinates.

$z_{l s}, z_{u s} \quad z$ positions of the lower and upper splines respectively.

$A_{1}$ Creep-ageing material constant related to effective creep strain rate.

$A_{2}$ Creep-ageing material constant related to rate of dislocation hardening.

$A_{3} \quad$ Creep-ageing material constant related to rate of dislocation density.

$B_{1} \quad$ Creep-ageing material constant related to effective creep strain rate.

C Constant for optimising a machining-induced residual stress profile.

$C_{10}$ Temperature-dependent material constant of a neo-Hookean elastomer.

$C_{a}$ Creep-ageing material constant related to the interaction between dislocations and shearable precipitates. 
$C_{r}$ Creep-ageing material constant related to rate of precipitate growth.

$C_{s}$ Creep-ageing material constant related to the size, modulus and electronic mismatch of the solute.

$C_{\rho} \quad$ Creep-ageing material constant related to rate of dislocation density.

$D_{1} \quad$ Temperature-dependent material constant of a neo-Hookean elastomer.

$E$ Young's modulus of elasticity.

$Q_{r} \quad$ Creep-ageing material constant representing the saturation limit for depletion of zinc solute atoms within an aluminium matrix.

$R^{2} \quad \mathrm{R}$-squared in statistics.

$T$ Creep-ageing temperature.

$T_{0}$ Room temperature.

$T_{A A} \quad$ Artificial ageing temperature.

$T_{S H T} \quad$ Solution heat treatment temperature.

$U$ Strain energy per unit of reference volume of a neo-Hookean elastomer.

$X$ Operation domain of a machining-induced residual stress profile.

$\alpha$ Coefficient of thermal expansion.

$\delta_{0} \quad$ Initial centre deflection of initially distorted plate.

$\delta_{f} \quad$ Final centre deflection of creep-age formed plate.

$\delta_{f}^{E x p}, \delta_{f}^{F E} \quad$ Experimental and FE-simulated final centre deflections of formed plate respectively.

$\varepsilon_{e}^{c r}, \dot{\varepsilon}_{e}^{c r} \quad$ Effective creep strain and its rate term respectively.

$\gamma_{r}$ Creep-ageing material constant controlling the effect of dislocation density (or creep) on precipitate nucleation and growth.

$\bar{\rho}_{d}, \overline{\bar{\rho}}_{d} \quad$ Normalised dislocation density and its rate term respectively.

$\bar{\rho}_{d}^{0} \quad$ Initial value for normalised dislocation density.

$\sigma_{\text {age }}, \dot{\sigma}_{\text {age }}$ Age hardening contribution to yield strength and its rate term respectively.

$\sigma_{a g e}^{0}$ Initial value for age hardening.

$\sigma_{d i s}, \dot{\sigma}_{d i s} \quad$ Dislocation hardening contribution to yield strength and its rate term respectively.

$\sigma_{e} \quad$ Von Mises equivalent stress.

$\sigma_{\text {res }}$ Machining-induced residual stress.

$\sigma_{\text {res }}^{\text {comp }}$ Maximum compressive stress level of a machining-induced residual stress profile.

$\sigma_{\text {res }}^{\text {tens }}$ Maximum tensile stress level of a machining-induced residual stress profile.

$\sigma_{\text {res }}^{\text {surf }} \quad$ Surface stress level of a machining-induced residual stress profile.

$\sigma_{\text {sol }}, \dot{\sigma}_{\text {sol }} \quad$ Solid solution hardening contribution to yield strength and its rate term respectively.

$\sigma_{\text {sol }}^{0} \quad$ Initial value for solid solution hardening.

$\sigma_{x}, \sigma_{y}$ Transverse stress and longitudinal stresses respectively. 
$\sigma_{y l d}, \sigma_{y l d}^{0}$ Current and initial yield strength respectively.

$\Delta$ Absolute difference between the experimental and FE-simulated final centre deflection of plates, $\Delta=\left|\delta_{f}^{E x p}-\delta_{f}^{F E}\right|$. 


\section{Introduction}

Creep-age forming (CAF) refers to a process that concurrently shapes and heat-treats aluminium alloy components. During creep-ageing, internal stresses within the material relax due to creep whilst its microstructure and mechanical properties change due to ageing. CAF has many advantages in comparison with conventional forming techniques for forming large integrally stiffened panel parts (Eberl et al., 2008; Zhan et al., 2011a) and existing applications of CAF can be found in the production of aircraft wing skin panels and isogrid structures of space launch vehicles (Islamoff, 1965; Bilstein, 1980; Holman, 1989; Levers, 2003).

In $\mathrm{CAF}$, the specific temperature-time combination of the creep-ageing thermal cycle is determined not for the shaping purpose, but to yield the desired mechanical properties of

the formed component. As a result, internal stresses of the loaded component cannot be fully relaxed and springback is inevitable (Holman, 1989; Ho et al., 2004a). In order to produce accurately shaped components that also satisfy the given strength requirement via CAF, collaborative efforts between the development of flexible tooling and process modelling techniques for springback compensation in CAF have been initiated (Levers, 2010; Zhan et al., 2011a; Lam et al., 2015a).

Accurate springback modelling for CAF requires the knowledge of stress states throughout the component immediately before unloading, which is controlled by the alloy's creep-ageing response. Unlike conventional creep, the primary creep stage is most important in $\mathrm{CAF}$, during which the creep rate plummets with an ongoing ageing response. In order to enable this unique material behaviour of CAF to be captured, an early attempt has been made by Ho et al. (2004b) who developed a set of constitutive equations for modelling the creepageing behaviour of 7000 -series aluminium alloys. The model is able to make predictions for creep deformation, precipitate radius growth and yield strength contributions from age hardening, dislocation hardening and solid solution hardening. A more recent material model developed by Zhan et al. (2011b) further introduces the concept of normalised precipitate size, normalised dislocation density as well as other key advancements. Both of these models are examples of physically based, unified creep-ageing constitutive equations that can be implemented into finite element solvers for CAF process modelling and springback prediction (Ho et al., 2004a; Lin and Dean, 2005; Lin et al., 2006; Zhan et al., 2011b). 
In addition to the alloy's deformation and hardening responses during creep-ageing, springback of sheet metals under the warm forming condition is also sensitive to various process parameters (Kim and Koç,. 2008). More relevant of these to CAF are friction condition, thermally-induced distortions and design of tooling (Yang et al., 2013). The use of finite element method further introduces numerical sensitivity to the problem in the form of numerical scheme, mesh density, element type and the number of through-thickness integration points in shell elements, to name but a few (Narasimhan and Lovell, 1999; Wagoner and Li, 2007; Wagoner et al., 2013).

As for large aerospace panel parts, extra materials are removed via machining before CAF submission (Levers, 2003; Birch, 2005). Machining operations would generate geometric distortions and a high level of surface residual stresses, which has been studied extensively in terms of machining techniques (El-Khabeery and Fattouh, 1989; Rao and Shin, 2001; Ee et al., 2005; Ulutan et al., 2007; Denkena et al., 2008; Tang et al., 2009) but has not yet been considered in springback predictions for CAF. The machined plate normally contains different thickness at different sections. For example, the thickness of an aircraft wing skin panel can vary from less than $5 \mathrm{~mm}$ to up to over $30 \mathrm{~mm}$ within the same component (Levers, 2008). The effect of part distortion and surface residual stresses due to machining on springback has not been studied for CAF of aluminium plates of different thicknesses. The work described in this paper is the first time where a thorough understanding of this topic is provided through experimentation and finite element analysis.

In this paper, a brief analysis on the cause, key features and potential influence of machining-induced residual stresses is first presented. Details of a CAF test programme are then presented. The aim of carrying out the forming tests was to enable the evaluation of springback behaviour of surface-machined aluminium plates with different thicknesses. Finite element models have been developed for CAF process simulations with and without the consideration of machining-induced residual stresses and initial part distortion. The simulation results have been validated by the CAF test results, further simulations and analyses have been carried out and conclusions are given at the end of the paper.

\section{Residual stresses in processed and machined 7000-series aluminium alloys}

\subsection{Cause}

Figure 1 shows a typical processing route for 7000-series aluminium plates of T651 temper that had been subjected to surface machining prior to receive for CAF. The material is 
subjected to solution heat treatment at temperature $T_{S H T}$ for soaking time $t_{S H T}$ and then quenched to room temperature $\left(T_{0}\right)$ to produce a supersaturated solid solution. After stretching at $T_{0}$ for stress relief and first-stage-ageing at $T_{A A}$ to make the microstructure stable, the residual stresses within the aluminium plate is very low, normally about $15 \mathrm{MPa}$ in both the rolling and transverse directions (Prime and Hill, 2002; Robinson et al., 2012).

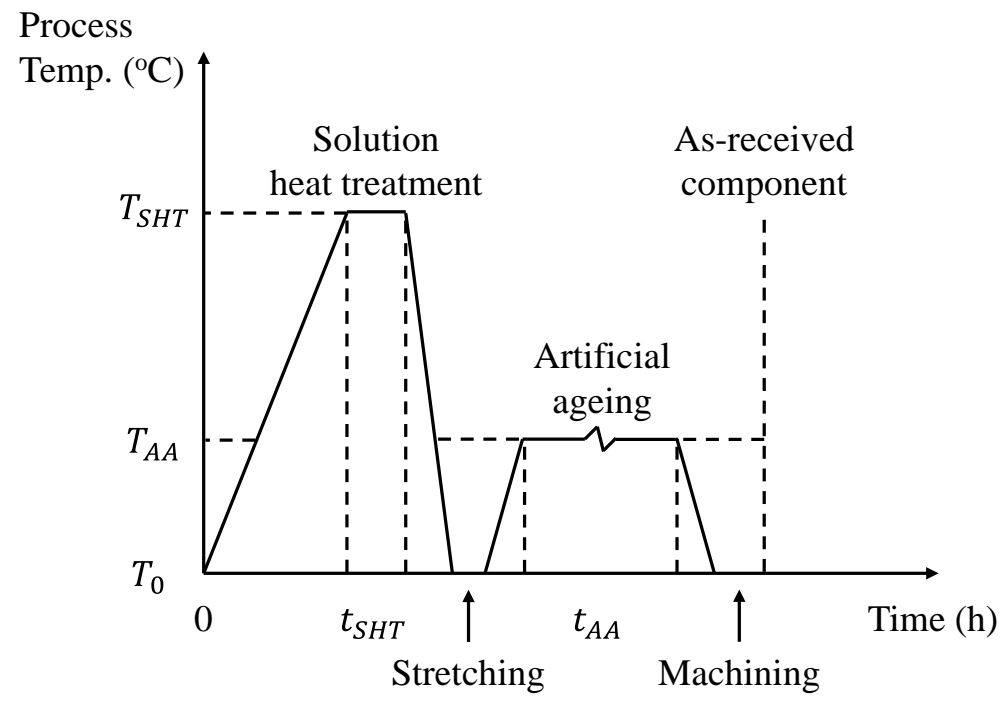

Figure 1. A typical processing route for 7000-series aluminium plates in T651 temper that had been subjected to surface machining prior to receiving for CAF.

For aerospace skin applications, the T651-tempered component is further submitted to high-speed machining where typically over $90 \%$ of the initial material volume is removed for integral features such as stringers and strip surfaces to be produced (Munroe et al., 2000). High level of surface residual stresses is generated as a result of the complicated thermalmechanical loading conditions experienced by the component during machining. These residual stress profiles can be affected by the individual influence of, or interactions amongst, machining parameters (El-Khabeery and Fattouh, 1989), cutting temperature (Ulutan et al., 2007), boundary and loading conditions (Denkena et al., 2008), as well as the cutting tool's material (Rao and Shin, 2001), geometry (Ee et al., 2005) and even its degree of wear (Tang et al., 2009).

\subsection{Key features}

\subsubsection{Machining-induced residual stress field}

For ease of description, the equations that together describe a symmetric machining-induced residual stress field, $\sigma_{r e s}$, are first listed. For $-h / 2 \leq z \leq(-h / 2+d)$ (Young et al., 2005) 


$$
\sigma_{\text {res }}(z)=\left(z+\frac{h}{2}\right)\left(\frac{\sigma_{\text {res }}^{\text {surf }}-\sigma_{\text {res }}^{\text {comp }}}{-d}\right)+\sigma_{\text {res }}^{\text {surf }}
$$

for $(-h / 2+d) \leq z \leq(h / 2-d)$

$$
\sigma_{\text {res }}(z)=\left(\sigma_{\text {res }}^{\text {comp }}-C\right)\left[\frac{e^{-20(X+1)}+e^{+20(X-1)}}{2}\left(3 X^{2}-1\right)\right]+C,
$$

and for $(h / 2-d) \leq z \leq h / 2$

$$
\sigma_{\text {res }}(z)=\left(z-\frac{h}{2}\right)\left(\frac{\sigma_{\text {res }}^{\text {surf }}-\sigma_{\text {res }}^{\text {comp }}}{d}\right)+\sigma_{\text {res }}^{\text {surf }}
$$

where $z$ is the through-thickness location, $h$ is the plate thickness, $\sigma_{\text {res }}^{\text {comp }}$ and $\sigma_{\text {res }}^{\text {surf }}$ are respectively the maximum compressive stress and surface stress of $\sigma_{\text {res }}, d$ is the depth where $\sigma_{\text {res }}^{\text {comp }}$ is observed and $C$ and $X$ are contained in the following descriptions of Eqs. (1) - (3).

Figure 2 shows a typical $\sigma_{\text {res }}$ profile that was reconstructed using Eqs. (1) - (3). In Figure $2, \bar{z}$ is the normalised thickness such that $\bar{z}=z / h$.

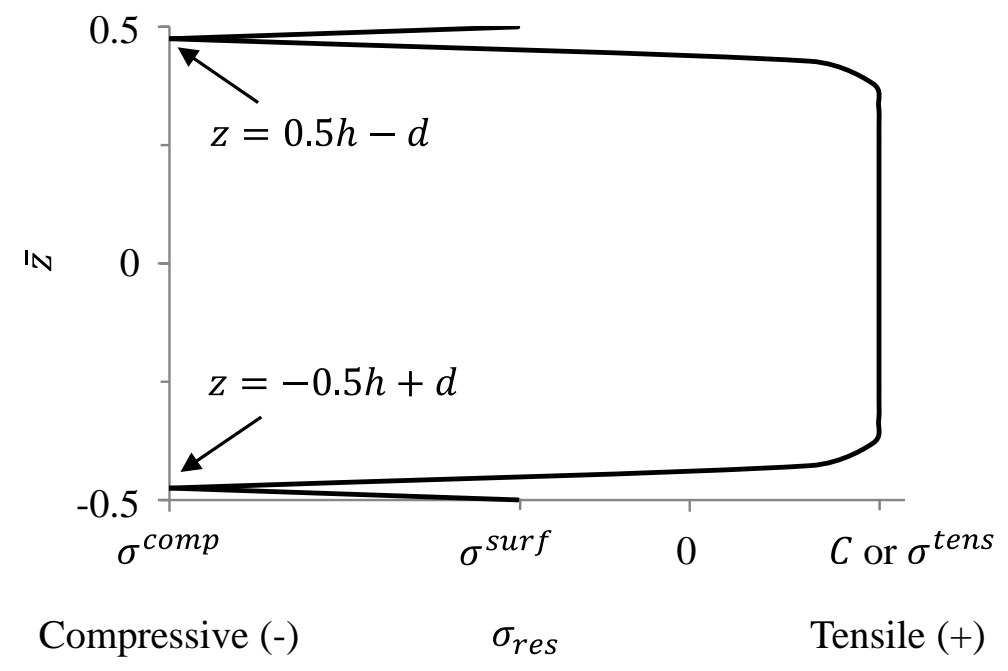

Figure 2. Key features of a typical machining-induced residual stress profile through the normalised plate thickness.

$\sigma_{\text {res }}^{\text {comp }}$ does not exist on the machined surfaces but within the subsurface region (Brinksmeier et al., 1982). Eq. (1) describes the linear subsurface $\sigma_{\text {res }}$ that grows from $\sigma_{\text {res }}^{\text {surf }}$ on the bottom plate surface to $\sigma_{\text {res }}^{\text {comp }}$ at a depth of $d$ above the bottom surface. Young et al. (2005) investigated machining-induced residual stress and distortion and a family of basis functions was proposed in order for them to determine the possible stress distributions that could have led to the distortions they observed in their experiments. One of the basis functions was adapted in Eq. (2) and forms the core of $\sigma_{\text {res }}$. The basis function operates 
within the domain $-1 \leq X \leq 1$, exhibits large magnitudes near the machined surfaces and decays exponentially to small values towards the plate centre - these are the typical features of machining-induced residual stresses. The constant $C$ is required for $\sigma_{\text {res }}$ to satisfy force and moment equilibria. Finally, Eq. (3) describes the linear subsurface $\sigma_{\text {res }}$ for the top surface of the plate.

\subsubsection{Quantification of key features}

Table 1 summarises the values that quantify the key features of $\sigma_{\text {res }}$ based on literature findings. Results are tabulated for the average residual stress values in $\sigma_{\text {res }}$ (with standard deviation) due to machining operations performed on 7000-series aluminium alloys.

Table 1. A summary of the average (standard deviation) surface, maximum compressive and maximum tensile residual stress levels due to the surface machining operations performed on 7000-series aluminium alloys by the referenced studies.

\begin{tabular}{cccc}
$\sigma_{\text {res }}^{\text {surf }}(\mathrm{MPa})$ & $\begin{array}{c}\sigma_{\text {res }}^{\text {comp }} \\
(\mathrm{MPa})\end{array}$ & $\begin{array}{l}\sigma_{\text {res }}^{\text {tens }} \\
(\mathrm{MPa})\end{array}$ & References \\
\hline $25(97)$ & $-155(86)$ & $14(18)$ & $\begin{array}{l}\text { Denkena et al. (2008); Tang } \\
\text { et al. (2009); Huang et al. } \\
(2013)\end{array}$ \\
\hline
\end{tabular}

The $\sigma_{\text {res }}^{\text {comp }}$ usually appears at $d=22 \pm 8 \mu \mathrm{m}$ below a machined surface with its magnitude significantly greater than $\sigma_{\text {res }}^{\text {surf }}$ and $\sigma_{\text {res }}^{\text {tens. }}$. The latter two are on average in a low tensile state but can also be compressive at times; this is particularly so for the $\sigma_{\text {res }}^{\text {surf }}$ which exhibits a wide range of variation across stress states in the literature.

\subsection{Potential influence}

Initial deformation experienced by components in $\mathrm{CAF}$ is predominantly elastic and viscoplastic deformation is dependent on the current internal stress state of the component (Zhan et al., 2011b). Figure 3a shows the through-thickness schematic of a plate with the above-described $\sigma_{\text {res }}$ profile. As a reference, the typical $\sigma_{\text {res }}^{\text {comp }}$ in a surface-machined 7000series aluminium alloy is around -155 $\mathrm{MPa}$ (Table 1) and it has been reported that the creep activation von Mises equivalent stress of a similar alloy can be as low as $60 \mathrm{MPa}$ (Lam and Lin, 2014). Figure $3 \mathrm{~b}$ and Figure $3 \mathrm{c}$ show respectively the elastic loading and loaded stress profiles of the plate during CAF. Because of the presence of a high level, asymmetric (about the vertical axis) residual stress field, the shape of the elastic loading stress profile has been 
disturbed and position of the neutral surface has been shifted. It was hypothesised that such $\sigma_{\text {res }}$-inducted stress disturbances could lead to a change in the amount of creep strain accumulation in CAF, which may eventually influence springback prediction; and it is the purpose of this paper to report an investigation into this.

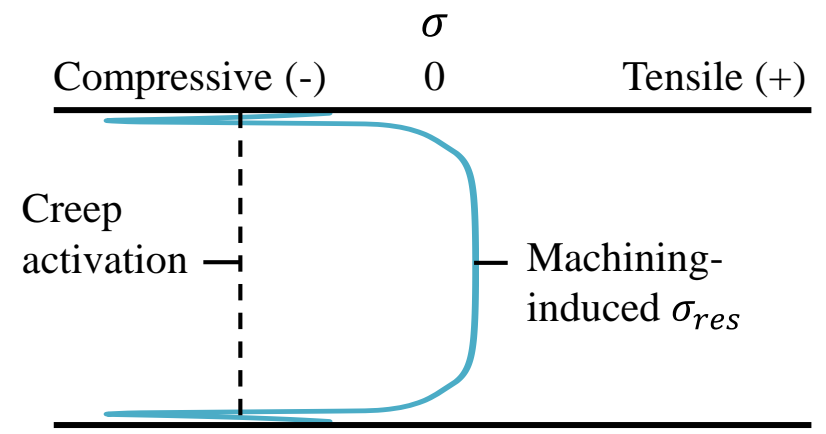

(a)

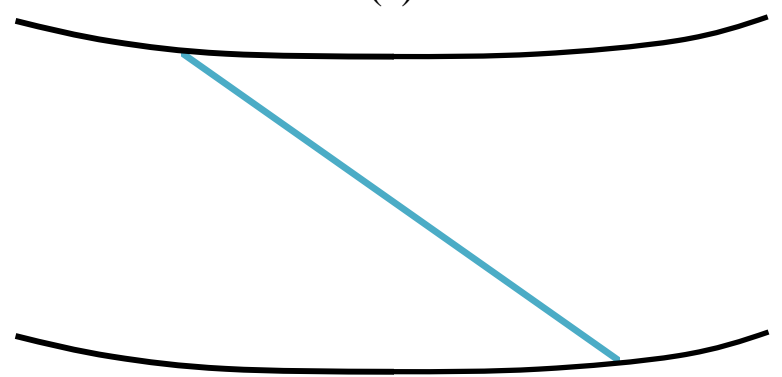

(b)

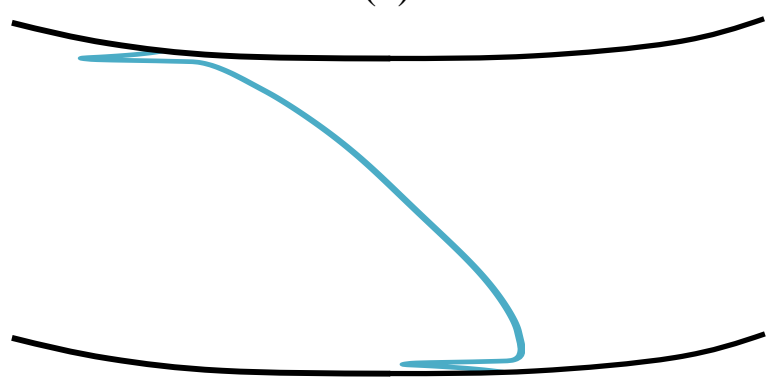

(c)

Figure 3. Through-thickness schematics of (a) a typical machining-induced residual stress profile, (b) elastic bending stress and (c) the resultant stress profile in a fully loaded plate with residual stress.

\section{Experimental details}

\subsection{Material}

7B04-T651 aluminium plates of dimensions $600 \mathrm{~mm} \times 350 \mathrm{~mm}$ in 3 to $8 \mathrm{~mm}$ thicknesses were supplied by AVIC BAMTRI (Beijing, PR China) in the longitudinal rolling orientation. Plate billets of $25 \mathrm{~mm}$ thickness had undergone solution heat treatment at $475{ }^{\circ} \mathrm{C}$ for $1 \mathrm{~h}$ followed by water quenching, $1.5 \%$ stretching for relieving residual stresses and artificial ageing at $115{ }^{\circ} \mathrm{C}$ for $24 \mathrm{~h}$ to get peak strength. The billets were then wire-cut through the thickness to approximate the requested thicknesses. The cut plates were eventually surface- 
machined prior to delivery. Figure 4a shows the gridlines that were drawn on all the plates upon receiving them. An average thickness value $(h)$ was obtained for each plate based on twenty measurements that were recorded at the gridline positions along the four edges of the plate using a pair of digital Vernier callipers.

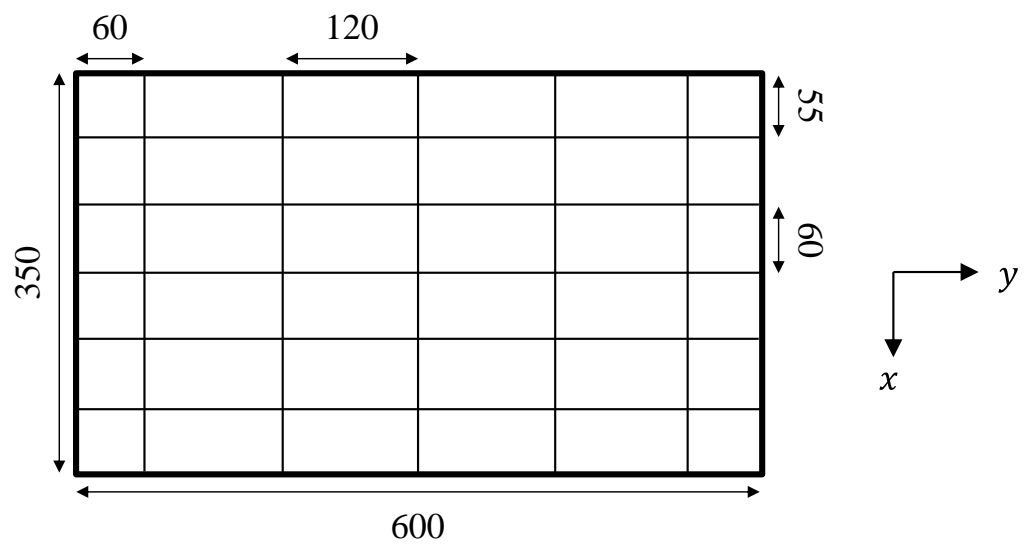

(a)

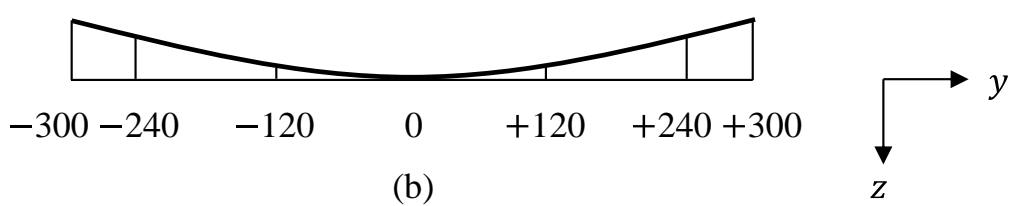

Figure 4. Schematics of (a) the gridlines drawn on the plates and (b) initial bending distortion and the locations where initial deflections were measured. Units are in millimetres.

\subsection{Initial distortion measurements}

All the plates had a various degree of initial distortion due to the presence of residual stresses after machining. The major mode of initial distortion was single curvature bending. In order to characterise the initial bending distortion, vertical differences between the $y$-plate-centre and the gridline positions, as depicted in Figure $4 \mathrm{~b}$, were measured using a digital height gauge. Three sets of measurements were obtained from each side of the plates at $x= \pm 175$ $\mathrm{mm}$, which results in twelve sets of half-length measurements. The results were then averaged to yield an average initial deflection profile for half a plate.

\subsection{Surface residual stress measurements}

Surface residual stress measurements were performed using a Pulstec $\mu$-X360 compact X-ray residual stress analyser (Pulstec Industrial Co Ltd, Wales, UK). The instrument has a penetration depth of $10 \mu \mathrm{m}$ from the surface and analysis was based on the diffracted $\mathrm{x}$-rays that were detected by an area detector. Strains were first determined from the acquired 
Debye-Sherrer ring and it was followed by the calculation of residual stress using the cosine $\alpha$ method (Woodward, 2014).

\subsection{Creep-age forming tests}

A flexible CAF tool, constructed based on the design method proposed by Lam et al. (2015a), was used for the CAF tests in this study. Figure 5a shows the CAF tool design and forming test setup with the top and bottom die holders each holding twenty-five forming pins. Further details of the CAF tool design and CAF test setup will become apparent as the corresponding numerical model is presented in a subsequent section. A 250 ton Instron (Norwood, MA, USA) servo-hydraulic testing machine was used for loading and unloading. Heat treatment cycles were carried out in a fan-assisted Aerotherm (Staffordshire, England, UK) box oven with a built-in digital microprocessor and independent overheat controls. A digital thermometer was used to monitor the temperature of the plates during creep-ageing. 


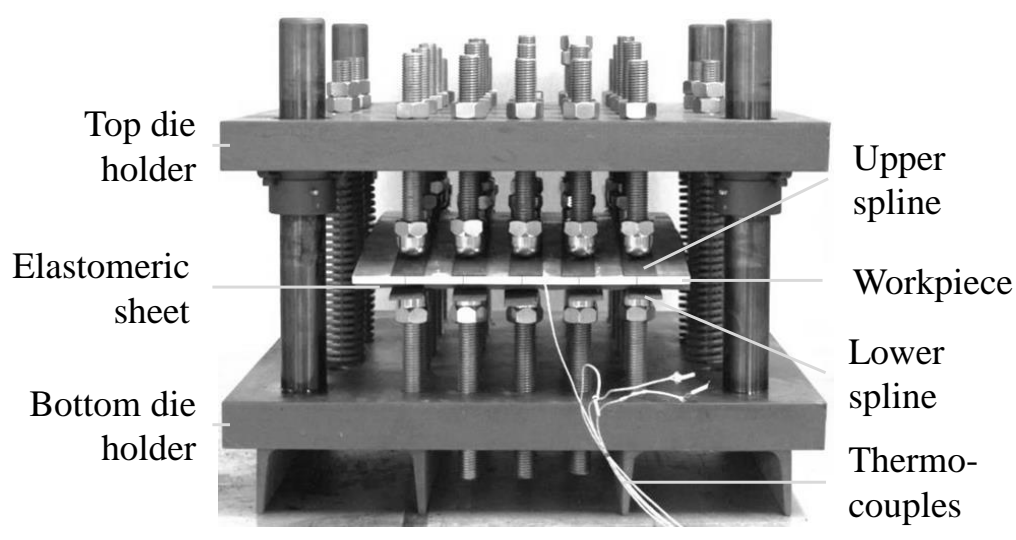

(a)

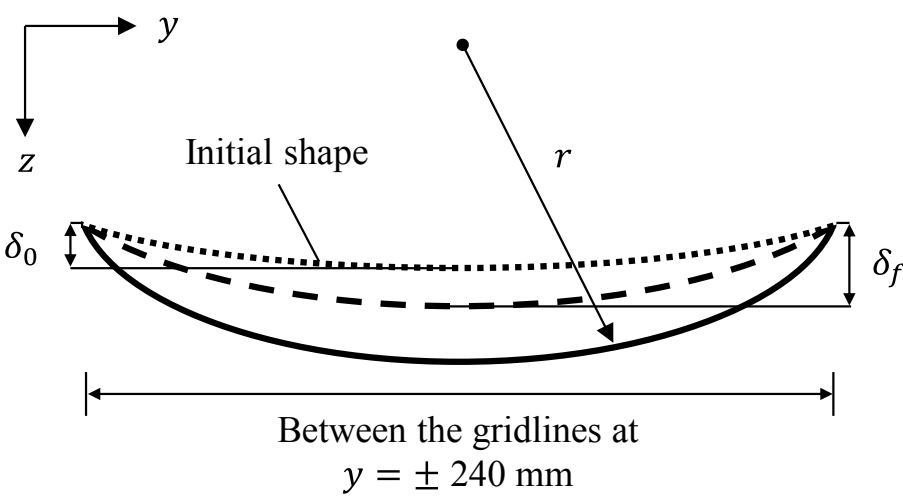

(b)

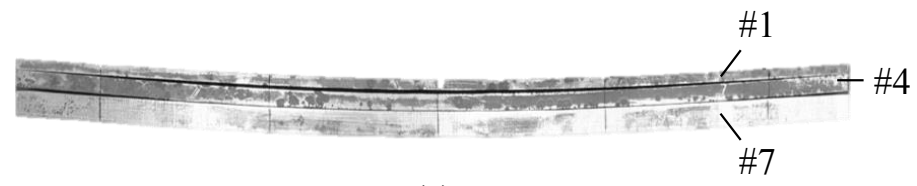

(c)

Figure 5. (a) The creep-age forming tool and test setup. (b) Definitions of the coordinate system, bending radius $(r)$, initial centre deflection $\left(\delta_{0}\right)$ and final centre deflection $\left(\delta_{f}\right)$. (c) Final curvatures of three of the formed plates in (\#1) 3.2, (\#4) 5.3 and (\#7) $8.2 \mathrm{~mm}$ thicknesses.

CAF tests were performed on all the plates using the same tooling setup which was designed to produce a single curvature bending radius $(r)$ of $1200 \mathrm{~mm}$. As illustrated in Figure 5b, the plates were positioned in such a way that the initial bending curvature always conforms to the loading curvature $r$. During loading, the punch velocity was $4 \mathrm{~mm} / \mathrm{min}$. During creep-ageing, the recorded plate temperature was maintained at $115 \pm 2{ }^{\circ} \mathrm{C}$. After unloading, final centre deflections $\left(\delta_{f}^{E x p}\right.$ ) of the unloaded plates were measured for springback to be characterised (Figure 5b). Only the profile shape between $y= \pm 240 \mathrm{~mm}$ was considered as the outer portions of the plates were outside the forming region of the CAF tool. 


\section{Experimental results}

An average surface residual stress value of $\sigma_{\text {res }}^{\text {surf }}=-43 \pm 19 \mathrm{MPa}$ was measured which is closer to the compressive end of the literature range (Table 1). Table 2 summarises the measured values of $h$, initial deflections and $\delta_{f}^{E x p}$ of the plates. The initial deflections measured at $y=240 \mathrm{~mm}$ are equivalent to $\delta_{0}$ in Figure $5 \mathrm{~b}$. The thinner plates tend to have larger initial deflections. No apparent trend is observed by making comparisons between $h$ and $\delta_{f}^{E x p}$ but the latter seems to have a certain degree of correlation with the initial deflections of the plates. Figure $5 \mathrm{c}$ shows the final curvatures of three of the formed plates (\#1, \#4 and \#7) in different thicknesses.

Table 2. Average thickness, initial deflections and final deflection of the plates.

\begin{tabular}{|c|c|c|c|c|c|c|}
\hline \multirow{2}{*}{$\#$} & \multirow{2}{*}{$h(\mathrm{~mm})$} & \multicolumn{4}{|c|}{ Initial deflections $(\mathrm{mm})$ at } & \multirow{2}{*}{$\delta_{f}^{E x p}(\mathrm{~mm})$} \\
\hline & & $y=0 \mathrm{~mm}$ & $y=120 \mathrm{~mm}$ & $y=240 \mathrm{~mm}$ & $y=300 \mathrm{~mm}$ & \\
\hline 1 & 3.20 & 0 & 0.67 & 1.75 & 2.42 & 3.27 \\
\hline 2 & 3.26 & 0 & 0.75 & 1.95 & 2.70 & 3.76 \\
\hline 3 & 4.88 & 0 & 0.50 & 2.50 & 3.50 & 4.99 \\
\hline 4 & 5.30 & 0 & 0.65 & 2.38 & 4.97 & 4.91 \\
\hline 5 & 5.31 & 0 & 0.06 & 0.10 & 0.12 & 2.53 \\
\hline 6 & 8.09 & 0 & 0.05 & 0.10 & 0.13 & 3.57 \\
\hline 7 & 8.20 & 0 & 0.35 & 0.70 & 0.88 & 4.51 \\
\hline
\end{tabular}

\section{Finite element modelling}

Finite element (FE) method was chosen for its past successful applications demonstrated in the modelling of creep-ageing behaviour (Zhan et al., 2011b), residual stresses (Koç et al., 2006) and springback of sheet metal parts (Ho et al., 2004a). Figure 6 illustrates a flowchart of the FE modelling process and detailed descriptions of the individual procedure are contained in the following subsections. 


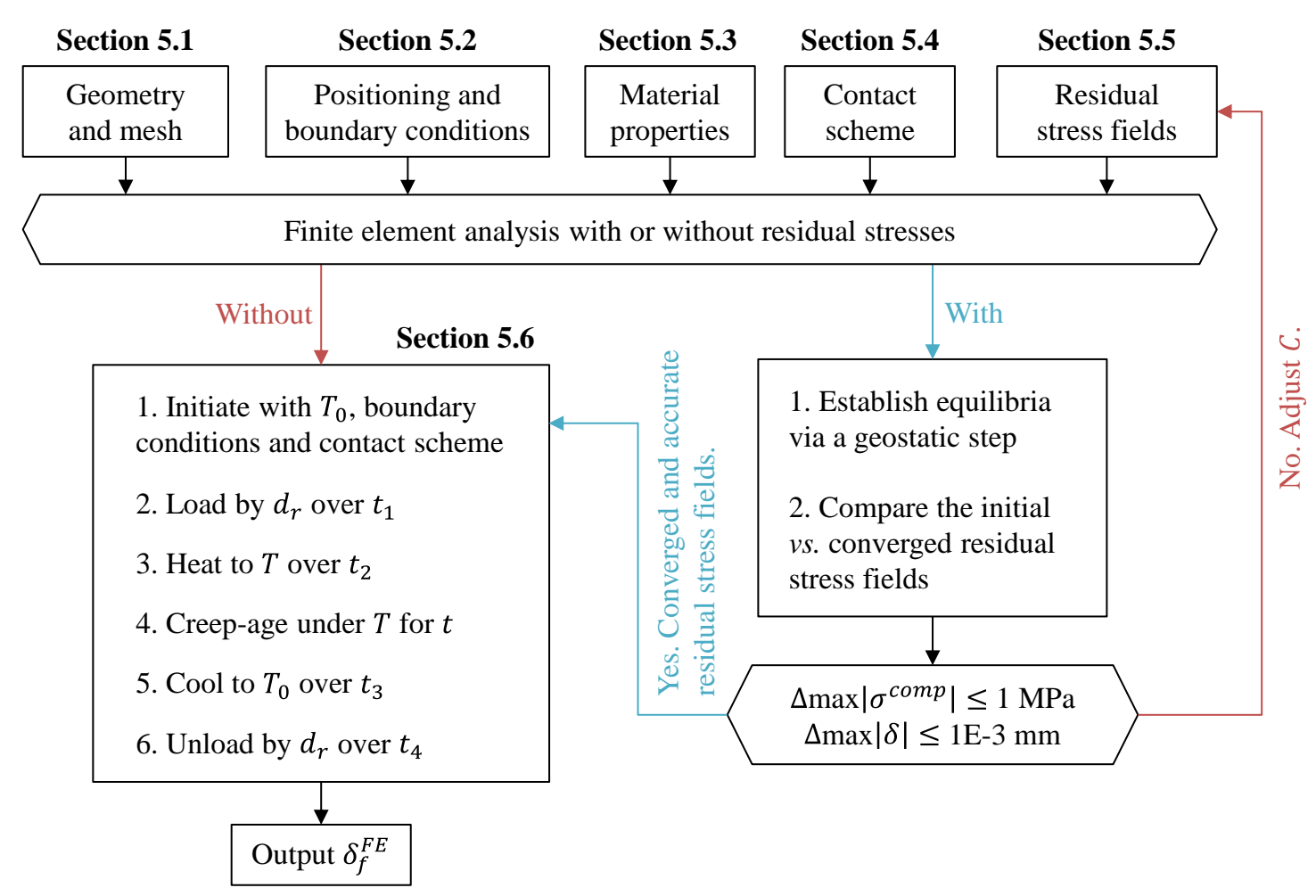

Figure 6. Flowchart of the finite element modelling process.

\subsection{Geometry and mesh}

Figure 7 shows an FE model of the flexible CAF tool constructed in Abaqus (v6.11, Dassault Systèmes Simulia, Providence, RI, USA). Only workheads of the forming pins were modelled which are assumed to be perfectly spherical with a radius of $r_{w}=14.65 \mathrm{~mm}$. The workheads were modelled using four-node discrete rigid elements R3D4.

In order to study both the individual and combined effects of residual stresses and initial distortion on springback, three cases were simulated under the conditions presented in Table 3. As further detailed research will be needed to provide scientific insights into the relationship between initial distortions, residual stress fields as well as the corresponding processes and processing conditions that caused them, the possible relationship between them is not considered in this work. This is achieved by modelling the initial distortion and residual stress field in the form of geometric model and initial stress field respectively. Whilst details about the latter is provided in a subsequent section, the flat plates were modelled using flat shells built in the conventional way whilst initial distortion (ID) and initial distortion with the consideration of residual stresses (ID-RS) of the plates were taken into account by creating a unique geometric model for each plate. For each ID or ID-RS plate model, four points were created, each point was positioned to the $y z$ coordinates that correspond to the measured 
initial deflections (Table 2), the four points were connected using a spline function and the connected spline was extruded to a depth of $175 \mathrm{~mm}$ in the $x$ direction to represent the width of a quarter plate.

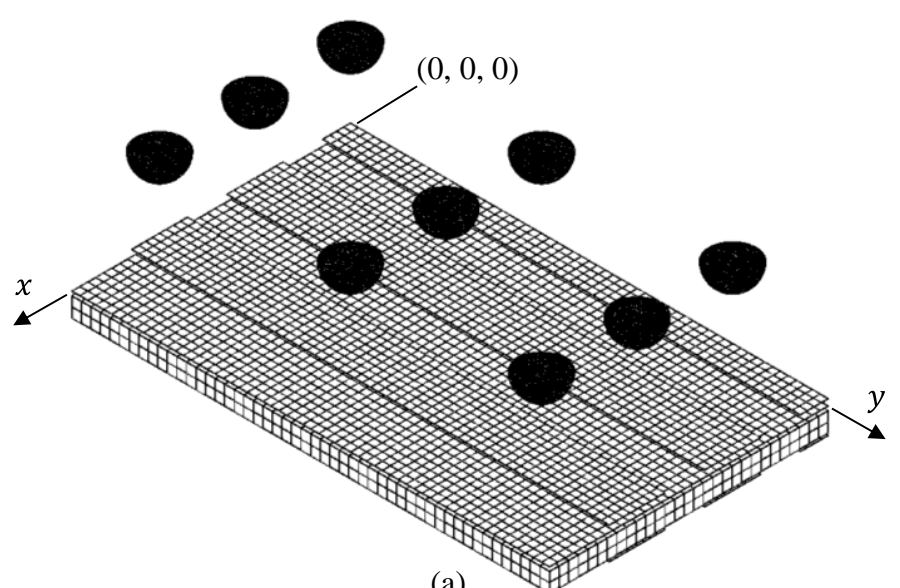

(a)

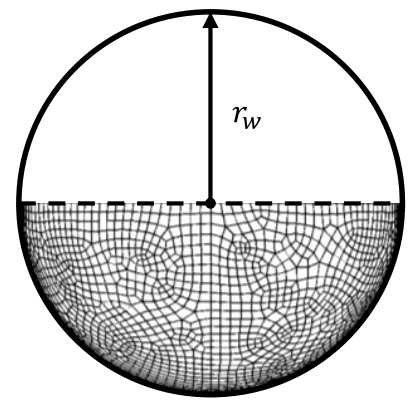

(b)

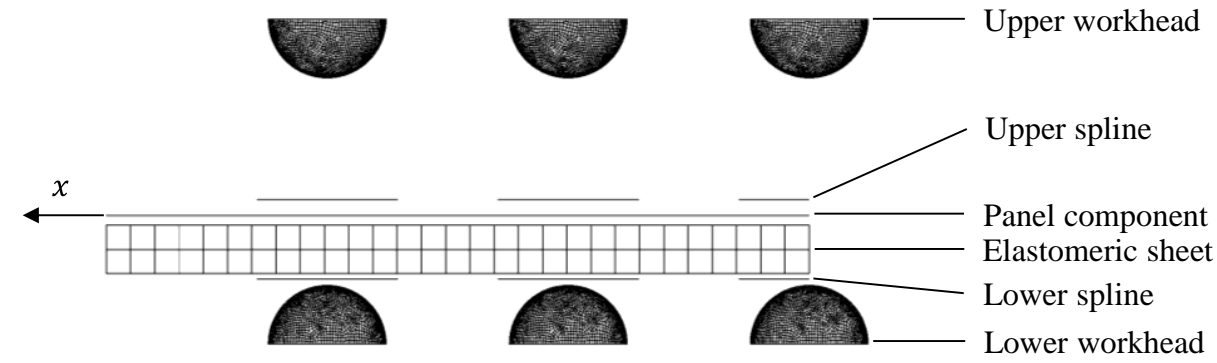

(c)

Figure 7. (a) Isometric view of the finite element model. (b) Finite element mesh of a workhead with an arbitrary revolving axis (dashed line) and the radius of revolvement, $r_{w}$. (c) $x z$ plane view of the finite element model with the different parts illustrated.

Table 3. Simulation conditions of the three cases.

\begin{tabular}{lcc}
\hline Case & Initial distortion & Residual stress \\
\hline Flat & No & No \\
ID & Yes & No \\
ID-RS & Yes & Yes \\
\hline
\end{tabular}

A summary of the element and geometric properties assigned to the different parts are presented in Table 4. Mesh convergence studies were carried out on one-mesh-at-a-time on the deformable meshes of the splines, elastomeric sheet and panel component. The final conditions of the convergent FE meshes are presented in Table 5. Convergences were achieved for the shape of the splines and both the shape and stress state of the panel component. For the workheads which were modelled as rigid bodies, the mesh of each workhead was globally seeded with an approximate global size of $0.05 r_{w}$ to ensure smooth contact surfaces. 
Table 4. Element and geometric properties assigned to the different parts.

\begin{tabular}{lccc}
\hline \multicolumn{1}{c}{ Part name } & Element type & $\begin{array}{c}x \times y \times z \\
\text { dimensions }(\mathrm{mm})\end{array}$ & $\begin{array}{c}\text { Number of through-thickness } \\
\text { Simpson's integration points }\end{array}$ \\
\hline Upper workheads & R3D4 & - & - \\
Upper splines & S4R & $35^{*} \times 300 \times 3$ & 31 \\
Panel component & S4R & $175 \times 300 \times h$ & 99 \\
Elastomeric sheet & C3D8RH & $175 \times 300 \times 12$ & - \\
Lower splines & S4R & $35^{*} \times 300 \times 3$ & 31 \\
Lower workheads & R3D4 & - & - \\
\hline
\end{tabular}

* The widths of the upper and lower splines in the middle along $x=0$ are $17.5 \mathrm{~mm}$ due to $x$-symmetry.

Table 5. Number of elements and equivalent approximate global size of the convergent meshes.

\begin{tabular}{lcc}
\hline \multicolumn{1}{c}{ Mesh } & Number of elements & Approximate global size (mm) \\
\hline Full splines & 420 & 5 \\
Elastomeric sheet & 2900 & 6 \\
Panel component & 2100 & 5 \\
\hline
\end{tabular}

\subsection{Positioning and boundary conditions}

A graphical illustration of the model positions and boundary conditions applied is shown in Figure 8. Nine workheads were positioned in the $x y$ plane to match a quarter of the physical tool design; a centre workhead was first positioned at $x=y=0$ and the other workheads were positioned in a way so that they are spaced equidistantly by $x=60 \mathrm{~mm}$ and $y=120$ $\mathrm{mm}$ in the final configuration.

As illustrated in Figure 8a and Figure 8b, symmetric boundary conditions were applied along the lines of axes $x=0$ and $y=0$. An additional boundary condition, $u_{x}=0$, was assigned to the centre lines of the full splines to avoid slippage to occur in the $x$ direction. Boundary conditions of the rigid workheads were assigned through their reference points, which are at the tip of each workhead (Figure 8c). The lower workheads were all assigned with an encastré boundary condition and $z$-positioned according to the pin height requirement for $r=1200 \mathrm{~mm}$. Similarly, the upper workheads were fixed in all directions except in $z$, as each upper workhead were $z$-positioned and assigned with a unique displacement loading condition, $d_{r}$, specific to $r=1200 \mathrm{~mm}$. 


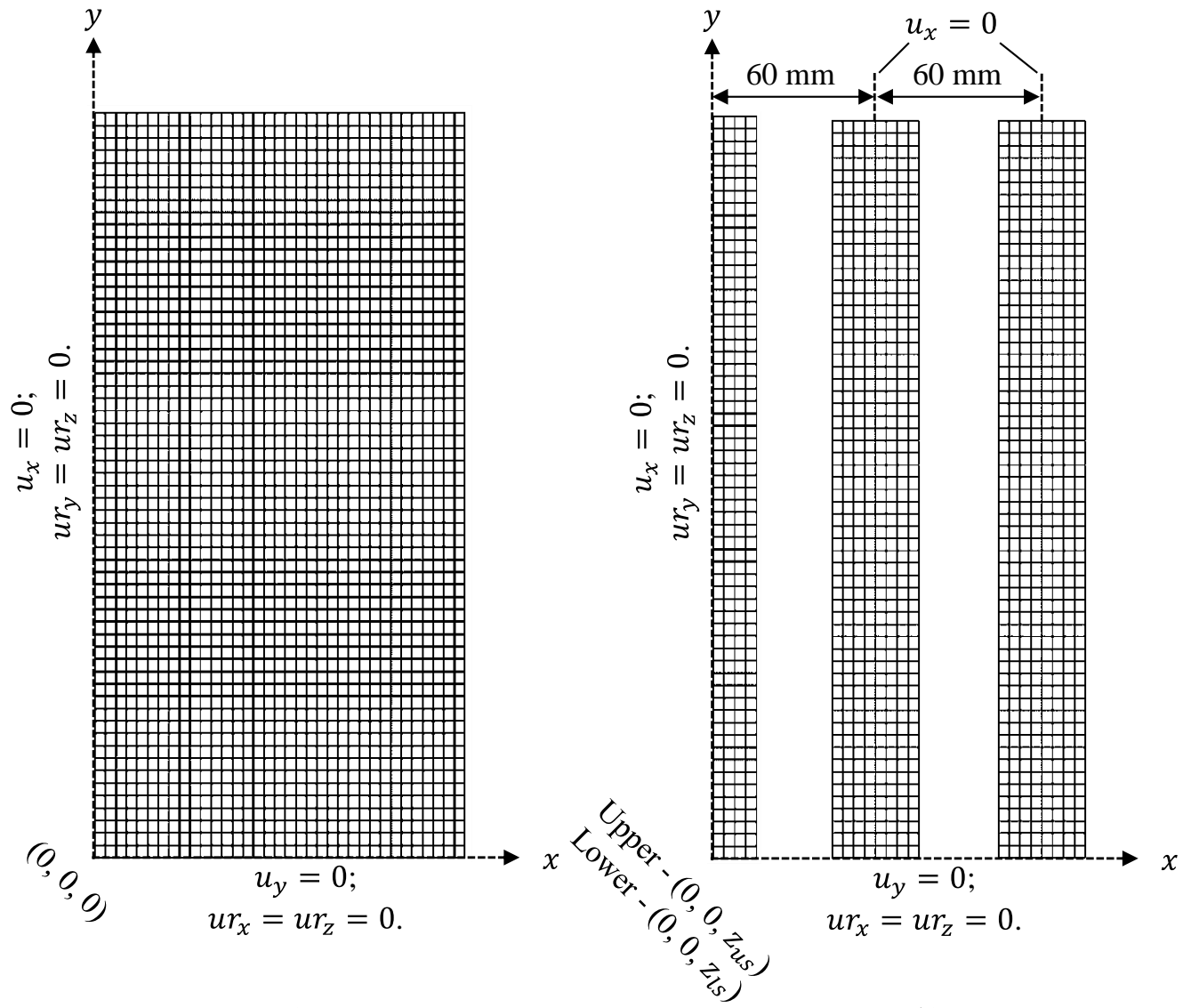

(a)

(b)

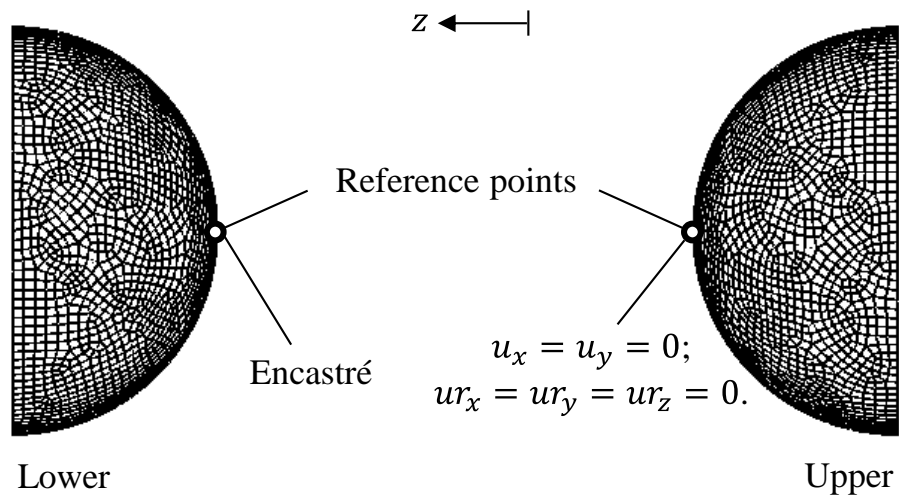

(c)

Figure 8. Positions and boundary conditions of (a) the panel component, (b) upper and lower splines and (c) an arbitrary pair of workheads (positions not specified).

\subsection{Material properties}

Table 6 summarises the material properties assigned to the different parts of the FE model where $E$ is the Young's modulus, $v$ is the Poisson's ratio and $\alpha$ is the coefficient of thermal expansion. The splines were modelled as spring-tempered steel and are not expected to experience any plastic deformation. The elastomeric sheet has a Shore A hardness of 60 and was modelled as an isotropic hyperelastic material using the neo-Hookean strain energy potential, $U$, which requires the input of two material parameters, $C_{10}$ and $D_{1}$ (Abaqus, 2011). 
Experimental and FE characterisation performed on the rubber and polyurethane under tension and compression at a low strain rate of $0.05 \mathrm{~s}^{-1}$ suggest that the value of $C_{10}$ for elastomers of the same hardness grade ranges between 1.3 and 1.6 MPa (Lam et al., 2011). A value of $C_{10}=1.45 \mathrm{MPa}$ was assigned to the elastomeric sheet and $D_{1}=0 \mathrm{MPa}$ which implies full incompressibility.

Table 6. Material properties assigned to the different parts.

\begin{tabular}{lcccc}
\hline \multicolumn{1}{c}{ Part name } & Material & $E(\mathrm{GPa})$ & $v$ & $\alpha\left(\mathrm{K}^{-1}\right)$ (Bhushan, 2000) \\
\hline Upper workheads & - & - & - & - \\
Upper splines & Spring steel & 210 & 0.3 & $1.3 \mathrm{E}-5$ \\
Panel component & 7B04-T651 & 67 & 0.33 & $2.3 \mathrm{E}-5$ \\
Elastomeric sheet & Silicone rubber & - & - & $2.5 \mathrm{E}-5$ \\
Lower splines & Spring steel & 210 & 0.3 & $1.3 \mathrm{E}-5$ \\
Lower workheads & - & - & - & - \\
\hline
\end{tabular}

The panel component was modelled as aluminium alloy 7B04-T651 with its creepageing behaviour described by Eqs. (4) - (10) and implemented via the user-defined subroutine CREEP.

$$
\begin{aligned}
& \dot{\varepsilon}_{e}^{c r}=A_{1} \sinh \left\{B_{1}\left[\sigma_{e}\left(1-\bar{\rho}_{d}\right)-k_{\varepsilon c} \sigma_{y l d}\right]\right\} \\
& \dot{\sigma}_{a g e}=C_{a} \dot{\bar{r}}_{p}^{m_{1}}\left(1-\bar{r}_{p}\right) \\
& \dot{\sigma}_{s o l}=-C_{s} \dot{\bar{r}}_{p}^{m_{2}}\left|\bar{r}_{p}-1\right| \\
& \dot{\sigma}_{d i s}=A_{2} \cdot n_{d} \cdot \bar{\rho}_{d}^{n_{d}-1 \dot{\bar{\rho}}_{d}} \\
& \sigma_{y l d}=\sigma_{s o l}+\sqrt{\sigma_{a g e}^{2}+\sigma_{d i s}^{2}} \\
& \dot{\bar{r}}_{p}=C_{r}\left(Q_{r}-\bar{r}_{p}\right)^{m_{3}}\left(1+\gamma_{r} \bar{\rho}_{d}^{m_{4}}\right) \\
& \dot{\bar{\rho}}_{d}=A_{3}\left(1-\bar{\rho}_{d}\right) \dot{\varepsilon}_{e}^{c r}-C_{\rho} \bar{\rho}_{d}^{m_{5}}
\end{aligned}
$$

In Eqs. (4) - (10), $A_{1}, B_{1}, k_{\varepsilon c}, C_{a}, m_{1}, C_{s}, m_{2}, A_{2}, n_{d}, C_{r}, Q_{r}, m_{3}, \gamma_{r}, m_{4}, A_{3}, C_{\rho}, m_{5}$ are material constants. This equation set was proposed by Zhan et al. (2011b) for describing concurrently the viscoplastic deformation, microstructural evolution and hardening mechanisms of 7000-series aluminium alloys in CAF. Whilst detailed descriptions of the 
equation set should be referred to Zhan et al. (2011b), the initial conditions and material constants used are presented in Table 7. The tabulated values had been determined by Lam et al. (2015b) using test-pieces produced from the same batch of materials as those of the plates in this study.

Table 7. Initial conditions and material constants for CAF of 7B04-T651 at $115^{\circ} \mathrm{C}$ for up to $22 \mathrm{~h}$ (Lam et al., 2015b).

\begin{tabular}{|c|c|c|c|c|c|c|c|c|}
\hline \multicolumn{9}{|c|}{ Initial conditions } \\
\hline & \multicolumn{2}{|c|}{$\sigma_{\text {sol }}^{0}(\mathrm{MPa})$} & $\sigma_{\text {age }}^{0}(\mathrm{MPa})$ & $\overline{\sigma_{y}^{0}}$ & ${ }_{d}(\mathrm{MPa})$ & $\bar{\rho}_{d}^{0}$ & & \\
\hline & \multicolumn{2}{|c|}{190} & 347 & & 537 & $1 \mathrm{E}-5$ & & \\
\hline \multicolumn{9}{|c|}{ CAF material constants } \\
\hline$A_{1}\left(\mathrm{~h}^{-1}\right)$ & $B_{1}\left(\mathrm{MPa}^{-1}\right)$ & $k_{\varepsilon c}$ & $C_{a}(\mathrm{MPa})$ & $m_{1}$ & $C_{s}(\mathrm{MPa})$ & $m_{2}$ & $A_{2}(\mathrm{MPa})$ & $n_{d}$ \\
\hline $1.95 \mathrm{E}-6$ & 0.042 & 0.16 & 4 & 0.9 & 0.2 & 0.45 & 260 & 0.7 \\
\hline$C_{r}\left(\mathrm{~h}^{-1}\right)$ & $Q_{r}$ & $m_{3}$ & $\gamma_{r}$ & $m_{4}$ & $A_{3}$ & $C_{\rho}\left(\mathrm{h}^{-1}\right)$ & $m_{5}$ & \\
\hline 0.098 & 1.8 & 2.2 & 3 & 2 & 150 & 0.145 & 1.5 & \\
\hline
\end{tabular}

\subsection{Contact scheme}

Tangential behaviour was modelled using isotropic penalty formulation with friction coefficients of 0.2 and 0.25 assigned between the elastomer-metal (Dirikolu and Akdemir, 2004) and aluminium-steel (Foster et al., 2009) interactions respectively. The accuracy of these friction coefficients is not known but they are used for this work due to the absence of any other data available.

\subsection{Residual stress fields}

The residual stress field used in this study was reconstructed and quantified based on the measured surface residual stress value (Section 4) and the related findings reported by researchers in the field (Section 2.2). This study further assumes that the stretching operation has eliminated most of the residual stresses in the plates prior to the surface machining operation. Therefore, the residual stress fields considered in this study is due only to the final finishing machining operation.

Residual stress fields of the plates were assigned via the through-thickness integration points (IPs) of the shell elements. In order to ensure as accurate as possible a representation of the residual stress fields, the Simpson's rule was employed with ninety-nine IPs which is the largest number that Abaqus supports. The restriction on the number of IPs in Abaqus has 
two implications. (i) An exact value of $d$ cannot be assigned but varies with $h$; this was $d=h / 99$. The potential effect of this difference in $d$ was assumed to be negligible due to the small range of $h$ variation in this study $(3.20$ to $8.20 \mathrm{~mm}$, which gives at most a $51 \mu \mathrm{m}$ difference in $d$ ). (ii) The residual stress field, $\sigma_{\text {res }}$, cannot be represented by a single equation - the surfaces and core values of $\sigma_{\text {res }}$ were assigned separately as a result. For the

first and the ninety-ninth IPs, a value of $\sigma_{\text {res }}^{\text {surf }}=-43 \mathrm{MPa}$ (the measured average) was directly assigned. For the second to the ninety-eighth IPs, which together represent the core of $\sigma_{\text {res }}$, the following procedure was followed: (i) Implement Eq. (2) into MATLAB (MathWorks, Natick, MA, USA) and assign it with $\sigma_{\text {res }}^{\text {comp }}=-155 \mathrm{MPa}$ (the literature average in Table 1). (ii) Split the core of $\sigma_{\text {res }}$ evenly into ninety-seven data points.

The same $\sigma_{\text {res }}$ profile was assigned to the transverse and longitudinal directions of the plate as the initial $\sigma_{x}$ and $\sigma_{y}$ via the user-defined subroutine SIGINI. A pilot simulation was run for each case in a geostatic step to establish force and moment equilibria for the initial $\sigma_{x}$ and $\sigma_{y}$. During the geostatic step, redistributions of $\sigma_{x}$ and $\sigma_{y}$ occur until equilibria are satisfied. At the same time, further distortions may occur depending on the difference between the initial and final converged stresses. Since initial distortions of the plates were already taken into account by the geometric models, the distortions that arise during the geostatic step are effectively unwanted displacements. The constant $C$ in Eq. (2) was therefore optimised so that as equilibria were satisfied, the change in maximum compressive stress due to stress redistribution and the maximum change in vertical displacement of the plate had to be smaller than $1 \mathrm{MPa}$ and $1 \mathrm{E}-3 \mathrm{~mm}$ respectively. The final $\sigma_{\text {res }}$ profile was reached for each plate upon satisfying both the equilibria and the criteria imposed on the change in maximum stress and vertical displacement at the same time.

\subsection{Numerical procedure}

A six-step modelling procedure was employed (Figure 6). Loading, heating, cooling and unloading were run in a general static step and creep-ageing was run in a visco step. As described earlier, the value $d_{r}$ in loading and unloading is a unique loading condition applied to each upper workhead and equals to the distance between the reference points of any pair of upper and lower workheads minus the sum of thicknesses of the upper splines, panel component, elastomeric sheet and lower splines. Table 8 presents the variables assigned which describe the temperature and loading profiles of the simulations (Figure 9). 


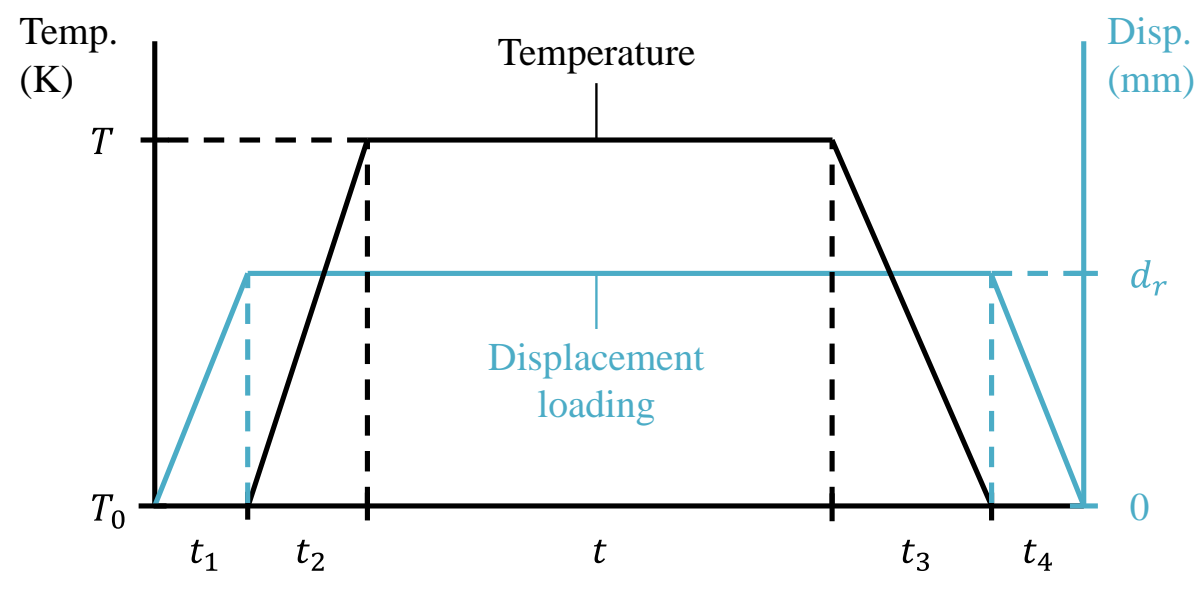

Time (h)

Figure 9. Schematics of the loading and temperature profiles.

Table 8. Variables that describe the temperature and loading profiles of the forming simulations.

\begin{tabular}{ccc}
\hline Variable & (Unit) & Assigned value \\
\hline$t_{1}$ & $(\mathrm{~h})$ & 0.1 \\
$t_{2}$ & $(\mathrm{~h})$ & 4 \\
$t$ & $(\mathrm{~h})$ & 22 \\
$t_{3}$ & $(\mathrm{~h})$ & 4 \\
$t_{4}$ & $(\mathrm{~h})$ & 0.1 \\
$T_{0}$ & $(K)$ & 295.15 \\
$T$ & $(K)$ & 388.15 \\
\hline
\end{tabular}

\section{Finite element modelling results}

Figure 10 illustrates comparisons of the $\delta_{f}^{E x p}$ with those simulated using $\mathrm{FE}\left(\delta_{f}^{F E}\right)$ under the three cases: Flat, ID and ID-RS. The plates were further categorised into two groups by their amount of initial deflections, $\delta_{0}$. Those in group $\mathrm{A}$ are the plates that have greater initial distortion $\left(\delta_{0}>1 \mathrm{~mm}\right)$, these are the 3.20, 3.26, 4.88 and 5.30-mm-thick plates. The plates in group B are those with $\delta_{0} \leq 1 \mathrm{~mm}$, which include the 5.31, 8.09 and 8.20-mm-thick plates. 


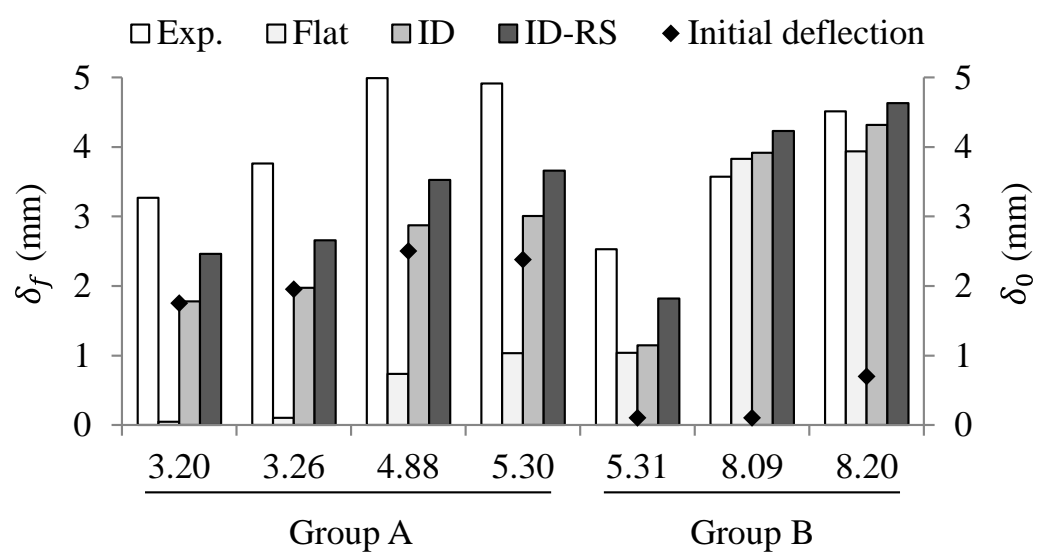

(a)

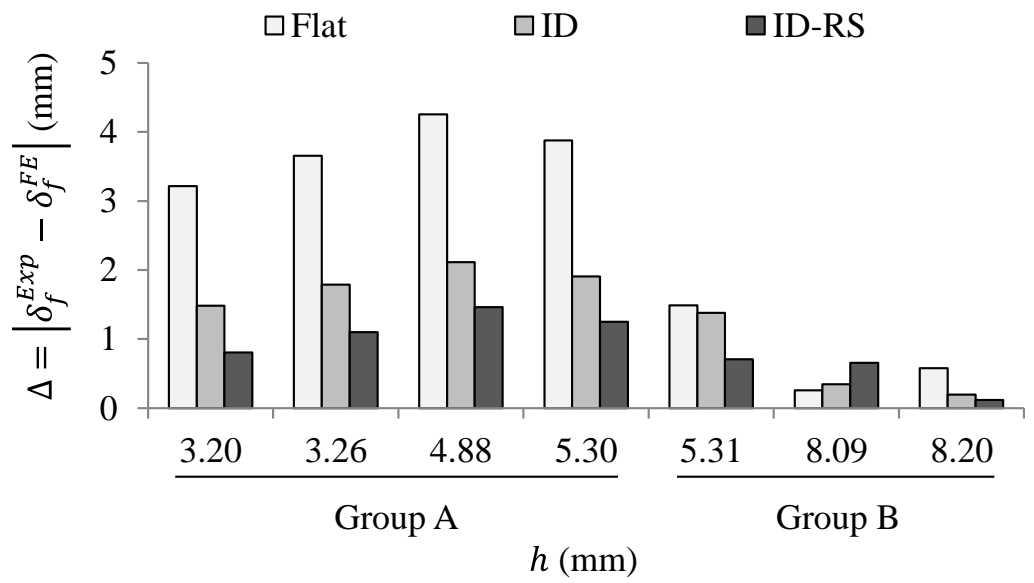

(b)

Figure 10. (a) Initial and final centre deflections of the plates. (b) Absolute differences between the experimental and simulated final centre deflections.

Table 9 summarises averages of the absolute differences between the experimental and FE-simulated deflections $\left(\Delta=\left|\delta_{f}^{E x p}-\delta_{f}^{F E}\right|\right)$ of the plates. $\delta_{f}^{F E}$ of the flat plates generally show greater deviations from $\delta_{f}^{E x p}$ (larger $\Delta$ ) than the other cases (ID and ID-RS). This deviation is more apparent for the plates with larger $\delta_{0}$ (group A). The plates in group A have an average $\delta_{0}$ of $2.15 \mathrm{~mm}$ and an average $\Delta$ of $3.75 \mathrm{~mm}$. On the other hand, for the plates in group $\mathrm{B}$, which have an average $\delta_{0}$ of $0.30 \mathrm{~mm}$, an average $\Delta$ of $0.78 \mathrm{~mm}$ is recorded.

For case ID, which has initial distortions of the plates taken into account by the geometric models, the average $\Delta$ of group A has reduced by $51.5 \%$ (from that of case Flat) to $1.82 \mathrm{~mm}$, that of group B has reduced less by $18.0 \%$ to $0.64 \mathrm{~mm}$ and that for all the plates has reduced by $46.8 \%$ to $1.32 \mathrm{~mm}$. 
Table 9. Group criterion, average initial deflection at $y=240 \mathrm{~mm}$ and average absolute differences between experimental and FE-simulated final centre deflections of the plates in group A and group B.

\begin{tabular}{cccccc}
\hline \multirow{2}{*}{ Group } & \multirow{2}{*}{ Criterion } & \multirow{2}{*}{ Average $\delta_{0}(\mathrm{~mm})$} & \multicolumn{4}{c}{ Average $\Delta(\mathrm{mm})$} \\
\cline { 4 - 6 } & & & Flat & ID & ID-RS \\
\hline A & $\delta_{0}>1 \mathrm{~mm}$ & 2.15 & 3.75 & 1.82 & 1.16 \\
B & $\delta_{0} \leq 1 \mathrm{~mm}$ & 0.30 & 0.78 & 0.64 & 0.50 \\
All the plates & - & 1.35 & 2.48 & 1.32 & 0.87 \\
\hline
\end{tabular}

The $\Delta$ values are smallest when simulations were performed with both the initial distortions and residual stress fields taken into account (case ID-RS). The average $\Delta$ values have dropped further (from that of case ID) by $36.3 \%$ to $1.16 \mathrm{~mm}$ for group A, by $21.9 \%$ to $0.50 \mathrm{~mm}$ for group B and by $34.1 \%$ to $0.87 \mathrm{~mm}$ when all the plates are considered altogether.

\section{Discussions}

\subsection{Influence of initial distortion on springback prediction}

Taking into account initial distortions of the plates has improved the $\delta_{f}$ prediction for the plates in group A significantly by an average of 51.5\%; whilst those for the plates in group B has also improved by an average of $18.0 \%$. Although the plates in group B are overall thicker, it does not imply that springback prediction for thicker plates are less affected by $\delta_{0}$. Figure 11 shows the strong positive correlation $\left(R^{2}=0.98\right)$ between the measured initial deflections of the plates $\left(\delta_{0}\right)$ and the predicted change in final centre deflections as a result of modelling initial distortions $\left(\left|\delta_{f}^{I D}-\delta_{f}^{\text {Flat }}\right|\right)$. It can be seen that for the 8.20 -mm-thick plate which has $\delta_{0}=0.70 \mathrm{~mm},\left|\delta_{f}^{I D}-\delta_{f}^{\text {Flat }}\right|$ has a value of $0.38 \mathrm{~mm}$ and this combination correlates well with the rest of the data points in the plot. This suggests that, at least applicable to within the limit of this study $(r \geq 1200 \mathrm{~mm}$ and $h \leq 8.2 \mathrm{~mm}$ ), the influence of initial distortion on springback prediction is not affected by the bend ratio, $r / h$. Rather, the overall greater improvement observed on the $\delta_{f}$ prediction for the thinner plates (group A: $51.5 \%$ ) than those for the thicker plates (group B: 18.0\%) is due to the fact that thinner plates in this study generally have greater $\delta_{0}$.

In the comparisons made between distortion measurements of a machined part and the corresponding distortion predictions, Young et al. (2005) found that machining-induced distortion takes on a very different shape from that due to bulk stress. More specifically, machining-induced distortion is dominated by asymmetric through-thickness shear stresses 
that cause a net twisting effect. On the other hand, the major mode of distortion due to the material's bulk stress was bending, which resembles that of the as-received plates in this study. Their prediction results show in general larger machining-induced distortions for thinner parts, which could be one of the contributing factors behind the overall larger $\delta_{0}$ measured from the thinner plates in group A.

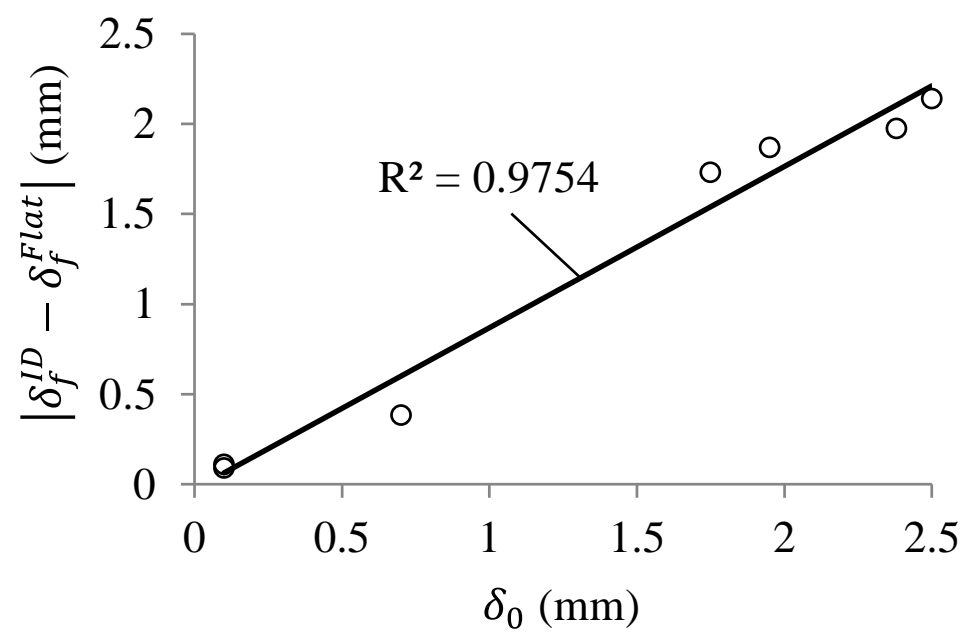

Figure 11. The positive correlation between initial deflection and absolute difference between final centre deflections of the plates simulated under cases Flat and ID.

In order to examine the possible effects of initial distortions that have on the stress states of components in CAF, comparisons between the through- $y$ stress distributions and creep strain accumulation of the 5.30 and 5.31-mm-thick plates are made. These comparisons enable better identification of the role of initial distortions alone as they have almost the same $h$ but different $\delta_{0}$. Figure 12 shows, for the bottommost tensile surfaces of the plates, the von Mises equivalent stress $\left(\sigma_{e}\right)$ after heating and the total accumulated effective creep strain $\left(\varepsilon_{e}^{c r}\right)$ after $22 \mathrm{~h}$ of creep-ageing along $y$ at $x=30 \mathrm{~mm}$ where there is no spline contact (Figure 8). In this study, the major mode of initial distortion of the plates is single curvature bending and the plates are loaded in a way such that the initial curvature always conforms to the bending curvature of the plates. As a result, the plate that has a greater $\delta_{0}$ was effectively bent less to achieve the same $r$, leading to an overall lower $\sigma_{e}$ state than the plate with less initial distortion.

Table 10 summarises the through- $y$ average $\sigma_{e}$ and $\varepsilon_{e}^{c r}$ of the 5.30 and 5.31-mm-thick plates. The difference is calculated using $|A-B| /[(A+B) / 2] \times 100$. The $10 \%$ higher overall $\sigma_{e}$ state of the plate with a lower $\delta_{0}$ translated to a significantly larger percentage difference in $\varepsilon_{e}^{c r}(51.9 \%)$. Despite the less $\varepsilon_{e}^{c r}$ accumulation in the plate with $\delta_{0}=2.38 \mathrm{~mm}$, 
$\delta_{f}^{E x p}$ of the plate is still $2.38 \mathrm{~mm}$ greater than that of the plate with $\delta_{0}=0.10 \mathrm{~mm}$ (Figure 10). Initial distortion therefore has opposing effects on the deformation in CAF; with initial distortions that conform to the bending curvature $r, \delta_{f}$ increases with increasing $\delta_{0}$ (Figure 11), but at the same time reduces the amount of additional deformation that would otherwise be induced by creep (Figure 12).

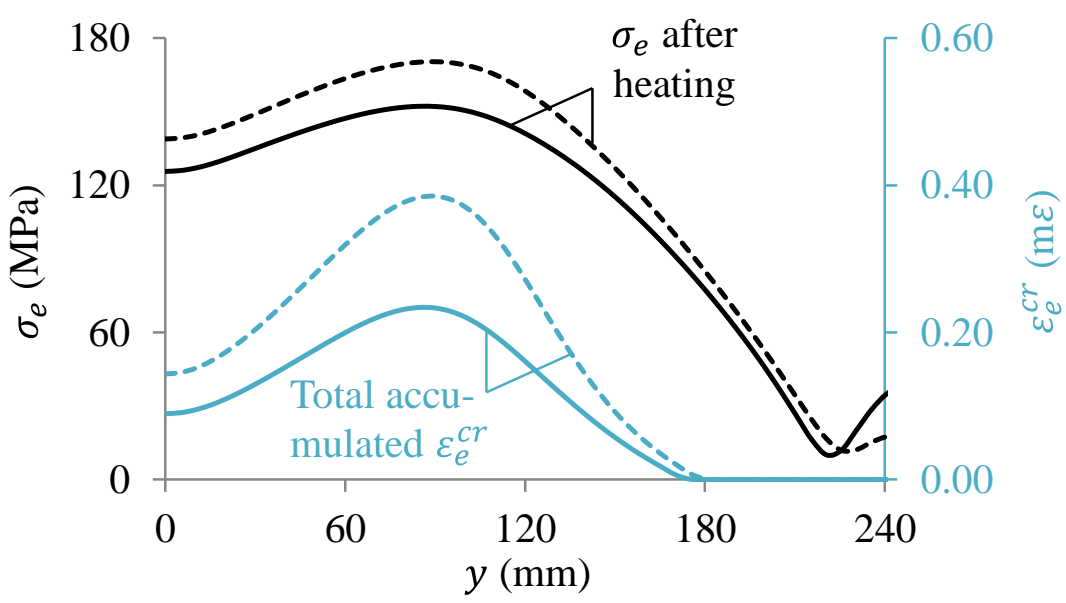

Figure 12. Through- $y$ von Mises equivalent stress after heating and total accumulated effective creep strain of the 5.30 and 5.31-mm-thick plates with $2.38 \mathrm{~mm}$ (solid lines) and 0.10 (dashed lines) initial deflections at $y=$ $240 \mathrm{~mm}$ respectively. Results were obtained at $x=30 \mathrm{~mm}$ on the bottommost tensile surface of the plates simulated under case ID.

Table 10. Through- $y$ average von Mises equivalent stress and effective creep strain of the two 5.3-mm-thick plates with different initial deflections.

\begin{tabular}{ccc}
\hline \multirow{2}{*}{$\delta_{0}(\mathrm{~mm})$} & \multicolumn{2}{c}{ Through-y average value of } \\
\cline { 2 - 3 } & $\sigma_{e}(\mathrm{MPa})$ & $\varepsilon_{e}^{c r}(\mathrm{~m} \varepsilon)$ \\
\hline 0.10 & 119.3 & 0.17 \\
2.38 & 107.9 & 0.10 \\
\hline Difference (\%) & 10.0 & 51.9 \\
\hline
\end{tabular}

\subsection{Influence of residual stress on springback prediction}

When both the measured initial distortions and typical residual stress fields are modelled together (case ID-RS), springback of all the plates was predicted to a remarkably good accuracy of $\Delta=0.87 \mathrm{~mm}$, which was 64.9 and $34.1 \%$ better than the predictions made under the cases Flat and ID respectively (Table 9).

However, Figure 10a shows that, except for the two thicker plates, the predicted $\delta_{f}^{I D-R S}$ are generally lower than $\delta_{f}^{E x p}$. This overestimation of springback may be attributed to the following two reasons: (i) In this study, initial distortions are modelled via the initial 
geometry of the FE model rather than the internal stresses that caused them. Therefore, although initial distortion has been taken into account, the internal stress states of the components prior to CAF submission remained underestimated. As viscoplastic deformation in CAF depends on the component's stress state (Eqs. (4) - (10)), the underestimation of stress state during CAF will translate to less deformation and springback overestimation. (ii) Due to the lack in the number of experimental investigations that report the magnitude of shear residual stresses in machined 7000-series aluminium alloys in the literature, only the initial $\sigma_{x}$ and $\sigma_{y}$ are taken into account in this study; this can also lead to an underestimation of component's stress state prior to CAF.

Figure 13 shows a good negative correlation $\left(R^{2}=0.85\right)$ between the measured plate thickness $(h)$ and the change in final centre deflections due to the modelling of residual stresses $\left(\left|\delta_{f}^{I D-R S}-\delta_{f}^{I D}\right|\right)$. Since a constant bending radius of $r=1200 \mathrm{~mm}$ was used in this study, this correlation seems to suggest that the modelling of $\sigma_{\text {res }}$ for accurate springback prediction becomes less important when a component is creep-age formed under a lower $r / h$ ratio (or higher bending stress level). To ease the following descriptions, two additional terms are introduced: (i) the upper compressive load region (CLR) and (ii) the lower tensile load region (TLR). In all cases, the upper CLR and the lower TLR each take a portion of $h / 2$ and are always divided by the plate centroid at $z=0 \mathrm{~mm}$.

To elucidate the possible mechanisms behind the above observation of Figure 13, comparisons are made in Figure 14 between the through-thickness $\sigma_{e}$ distributions of the thinnest 3.20-mm-thick (Figure 14a) and the thickest 8.20-mm-thick (Figure 14b) plates simulated under cases ID and ID-RS. $\sigma_{e}$ distributions are shown for the three key stages of CAF: (i) fully loaded and heated, (ii) after $22 \mathrm{~h}$ of creep-ageing and cooling and (iii) released from loading. Additionally, Table 11 presents comparisons of the through-thickness average $\sigma_{e}$ relaxation in the lower TLR and upper CLR of those plates.

Referring back to Figure 14a, which shows evolutions of the $\sigma_{e}$ distributions computed for the 3.20-mm-thick plate, when $\sigma_{\text {res }}$ prior to CAF was not included in the FE model (case ID), a linear through-thickness $\sigma_{e}$ distribution is observed in the heated plate. In general, constrained heating introduces a through-thickness compressive stress state to the plate; $\sigma_{e}$ in the upper CLR therefore has increased slightly when the plate is heated, whilst $\sigma_{e}$ in the lower TLR has slightly decreased. Since the 3.20-mm-thick plate was elastically loaded and only a little $\sigma_{e}$ relaxation took place during creep-ageing (Table 11), the final through- 
thickness $\sigma_{e}$ after the release of loading is almost negligible. This has resulted in the almost full springback of the plate upon release from loading for case ID (Figure 10a).

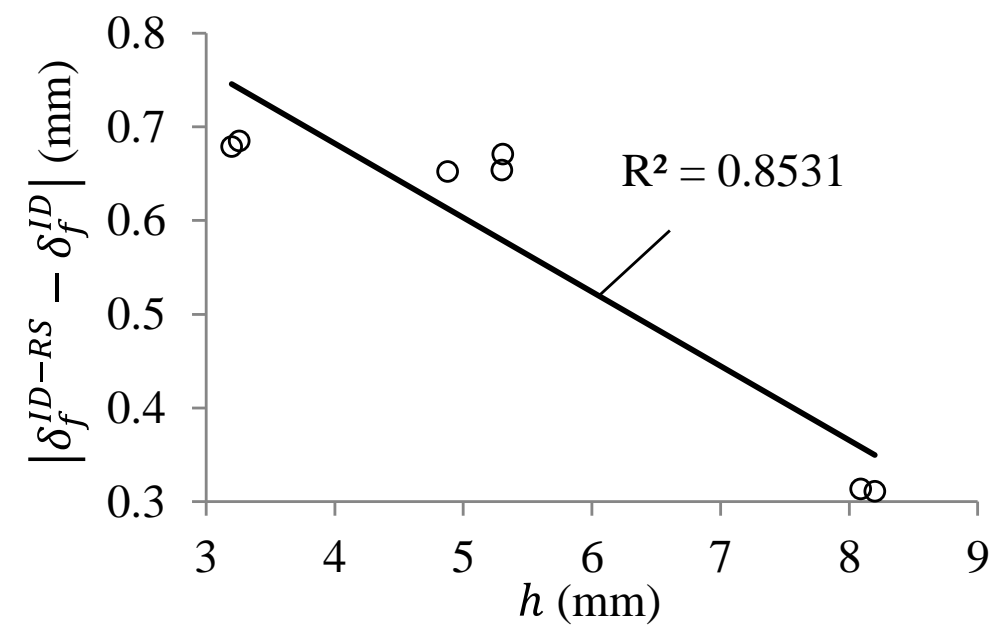

Figure 13.The negative correlation between plate thickness and absolute difference between final centre deflections of the plates simulated under cases ID and ID-RS.

When $\sigma_{\text {res }}$ exists in the 3.20-mm-thick plate (case ID-RS), the overall $\sigma_{e}$ relaxation was higher in the upper CLR and less in the lower TLR. In the upper CLR, more $\sigma_{e}$ relaxation is observed in the region where it overlaps with the compressive portion of the input $\sigma_{\text {res }}$. There is negligible creep activation in the other upper CLR where it overlaps with the tensile core of the $\sigma_{\text {res }}$. The position of the minimum $\sigma_{e}$ has shifted upwards by about 0.1 $\mathrm{mm}$ due to the tensile core feature of the $\sigma_{\text {res }}$. In the lower TLR, the positive contribution of the $\sigma_{\text {res }}$ tensile core to the tensile bending stress was still insufficient to cause any observable creep-induced $\sigma_{e}$ relaxation. The compressive portion of the $\sigma_{r e s}$ reduced the overall $\sigma_{e}$ state in the surface to subsurface region of the lower TLR, leading to the $31 \%$ less $\sigma_{e}$ relaxation (Table 11). As a result, the $\sigma_{e}$ in the lower TLR after tooling release takes almost the same shape as that of the $\sigma_{r e s}$. On the other hand, $\sigma_{e}$ relaxation in the upper CLR has relieved the peak $\sigma_{e}$ level by about $68 \mathrm{MPa}$ whilst the general $\sigma_{e}$ distribution still maintains the same basic shape as that of the $\sigma_{r e s}$. These phenomena have together resulted in a final $\sigma_{e}$ distribution that is asymmetric about the plate centroid of the 3.20-mm-thick plate (Figure $14 a)$. 


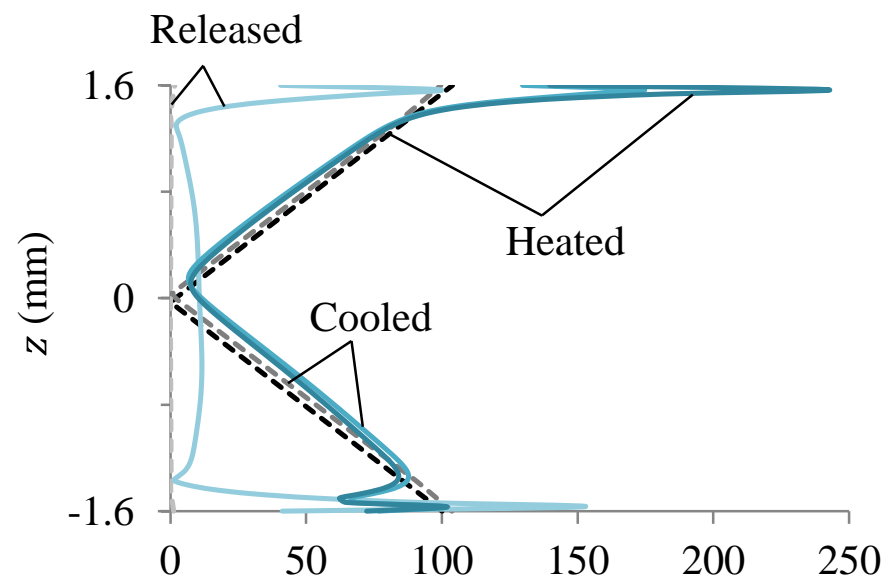

(a)

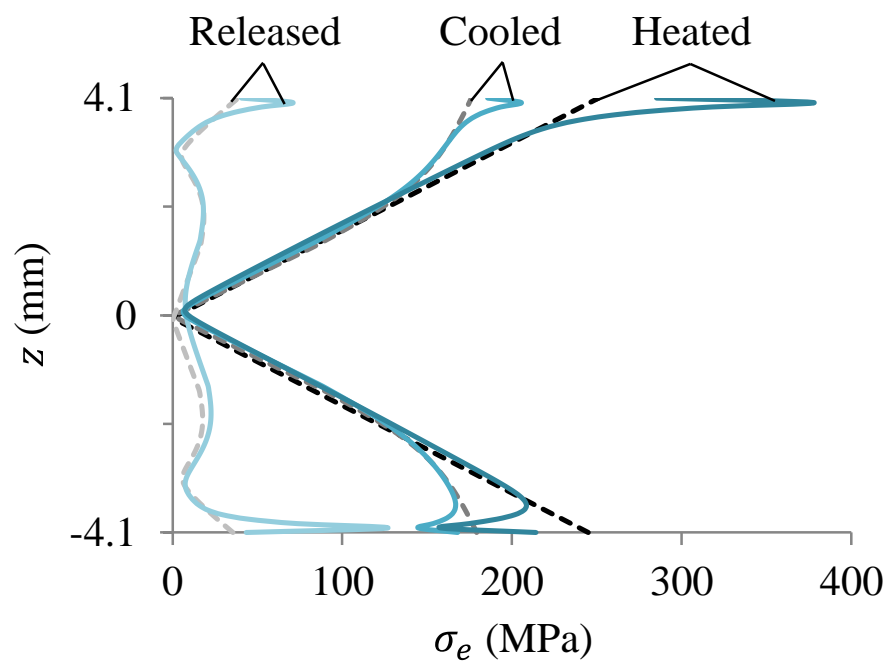

(b)

Figure 14. Through-thickness von Mises equivalent stress distributions at the key stages of creep-age forming for (a) the 3.20 and (b) 8.20-mm-thick plates under cases ID (dashed lines) and ID-RS (solid lines). Results were obtained from the element at $x=30 \mathrm{~mm}$ and $y=100 \mathrm{~mm}$.

Table 11. Through-thickness average von Mises equivalent stress relaxation in the lower tensile and upper compressive load regions (TLR and CLR) for the 3.20-mm and 8.20-mm-thick plates simulated under cases ID and ID-RS.

\begin{tabular}{clcccc}
\hline $\begin{array}{c}h \\
(\mathrm{~mm})\end{array}$ & Case & $\begin{array}{c}\text { Average } \sigma_{e} \text { relaxation in } \\
\text { the lower TLR }(\mathrm{MPa})\end{array}$ & $\begin{array}{c}\text { Change } \\
(\%)\end{array}$ & $\begin{array}{c}\text { Average } \sigma_{e} \text { relaxation in } \\
\text { the upper CLR }(\mathrm{MPa})\end{array}$ & $\begin{array}{c}\text { Change } \\
(\%)\end{array}$ \\
\hline 3.20 & ID & 4.2 & -31.0 & 3.1 & +32.3 \\
& ID-RS & 2.9 & & 17.7 & +26.6 \\
\hline
\end{tabular}

The bending stress level of the 8.20 -mm-thick plate is relatively high and has about $250 \mathrm{MPa}$ of maximum $\sigma_{e}$ on the surface even when $\sigma_{\text {res }}$ was not included in the model (Figure $14 \mathrm{~b}$ ). In the plate where there is no $\sigma_{\text {res }}$ (case ID), there exists a clear pure elastic 
region where no creep has occurred and an outer creep region where creep has been activated. This is a typical feature of thick plates in stress-induced creep forming condition, under which the elastic core is almost impossible to be completely eliminated (Ho et al., 2004a). The compressive portion of the $\sigma_{\text {res }}$ has increased the amount of $\sigma_{e}$ relaxation in the upper CLR by a maximum of $97.2 \mathrm{MPa}$. The tensile portion of the $\sigma_{\text {res }}$ has shifted the position of minimum $\sigma_{e}$ by almost the same amount of absolute distance as it did in the thinner plate. However, the shift is now relatively small due to the increased $h$. Of all the plates studied, the 8.20-mm-thick plate has the least differences in the $\sigma_{e}$ distributions between the two cases when $\sigma_{\text {res }}$ was (ID-RS) and was not modelled (ID). This is due to the higher bending stress level in the thicker plate relative to the constant $\sigma_{\text {res }}$ field; this suggests that the influence of residual stress on springback reduces with reducing $r / h$ ratio, which supports the observation in Figure 13.

\subsection{Asymmetric through-thickness stress relaxation}

The behaviour of asymmetric stress relaxation across the thickness of plates is apparent from the results tabulated in Table 11. To date, although the phenomenon of asymmetric stress relaxation had been observed in industrial $\mathrm{CAF}$, the underlying mechanism remains unclear. Bakavos et al. (2006) studied the through-thickness microstructural gradients in 7475 and 2022 post-CAF coupons. In their investigation, 20-mm-thick plates were creep-age formed at a $3180 \mathrm{~mm}$ single radius curvature tool using an autoclave and vacuum bagging system. The study revealed a $15 \%$ greater mean particle radius on the compression side than on the tension side and the authors suggested two possible causes of the observed phenomenon: (i) material anisotropy as a result of the residue Bauschinger effect left behind from the stretching operation (Figure 1) and (ii) asymmetric thermal-friction interactions due to the use of the vacuum bagging technique. The suggested reasons would both enable a faster stress relaxation in compression than in tension.

The modelling results in this article suggest that the presence of a compressive residual stress field in the surface to subsurface regions of plates prior to CAF can lead to faster compressive stress relaxation in $\mathrm{CAF}$. This may be applied more generally to the presence of any symmetric through-thickness residual stress field in plates prior to CAF. The microstructural changes during CAF, such as those mentioned above, may further contribute to the asymmetric through-thickness mechanical behaviour but discussion on this topic is beyond the scope of this paper. Although a much less effect in comparison to that due to 
residual stresses, through-thickness asymmetricity of stress due to thermal expansion of the plates under constrained heating has also been observed (Figure 14).

\section{Conclusions}

The influences of a typical machining-induced residual stress field and workpiece initial distortion on the accuracy of springback prediction in creep-age forming were experimentally and numerically investigated. This is the first time where their effects are studied in terms of springback prediction for the creep-age forming of panel components of different thicknesses. The following conclusions can be drawn:

- Initial distortions of plates, when conforming to the loading curvature, have opposing effects on deformation in creep-age forming. Conforming initial distortions contribute positively to the final formed shape but at the same time lead to less additional deformation introduced to the component being formed due to less creep strain accumulation during creep-ageing. In this study, a $2.3 \mathrm{~mm}$ difference in the initial centre deflection of two 600-mm-long, 5.3-mm-thick plates has led to over $50 \%$ difference in the average effective creep strain accumulated through the longitudinal direction of the plates. Taking into account the initial distortion of the plates in the geometric models has improved the prediction of final plate deflections by an average of $46.8 \%$, reducing the average vertical difference between experimental and simulated plate deflections from 2.48 to $1.32 \mathrm{~mm}$.

- Considering the machining-induced residual stresses in creep-age forming models leads to a higher overall stress state in the component being formed. This can cause greater accumulation of stress-induced creep strain that is sufficient to influence springback prediction. In this study, including the residual stress alone has reduced the difference between the experimental and simulated vertical plate deflections by $34.1 \%$, improving the average difference from 1.32 to $0.87 \mathrm{~mm}$.

- Influence of residual stresses on springback prediction in creep-age forming depends on the amount of deformation at the initial loading of the workpiece and its thickness. Given the presence of a constant residual stress field in a physical component, it becomes less important to consider the residual stress for springback prediction when the component is creep-age formed under a higher loading stress (for thicker plates for example). 
- A symmetric through-thickness residual stress field and thermal expansion under constrained heating can both contribute to the occurrence of asymmetric throughthickness stress relaxation during creep-age forming.

\section{Acknowledgments}

The strong support from Aviation Industry Corporation of China (AVIC) Beijing Aeronautical Manufacturing Technology Research Institute (BAMTRI) for this funded research is much appreciated. The research was performed at the AVIC Centre for Structural Design and Manufacture at Imperial College London. The authors would also like to express their appreciation to Mr Mike Woodward, Technical Support Manager of Pulstec Industrial Co Ltd Europe Office for his technical support on surface residual stress measurements.

\section{Conflict of interest}

The authors declare that there is no conflict of interest.

\section{References}

Abaqus (2011) Abaqus Analysis User's Manual 6.11. Dassault Systèmes Simulia, Providence, RI, USA.

Bakavos D, Prangnell PB, Bes B, Eberl F and Gardiner S (2006) Through thickness microstructural gradients in 7475 and 2022 creep-ageformed bend coupons. Materials Science Forum, 519-521, 407 - 412.

Bhushan B (2000) Modern Tribology Handbook, Two Volume Set. Boca Raton, CRC Press.

Bilstein RE (1980) Stages to Staurn: A technological history of the Apollo/Saturn launch vehicles. Washington DC, NASA History Office.

Birch S (2005) Technology update: Sizing up the A380's wings. SAE International. [Online].

Brinksmeier E, Cammett JT, König W, Leskovar P, Peters J and Tönshoff HK (1982) Residual stresses - Measurement and causes in machining processes. CIRP Annals Manufacturing Technology, 31(2), 491 - 510. 
Denkena B, Boehnke $D$ and de Leon $L$ (2008) Machining induced residual stress in structural aluminium parts. Production Engineering, 2(3), 247 - 253. [doi].

Dirikolu MH and Akdemir E (2004) Computer aided modelling of flexible forming process. Journal of Materials Processing Technology, 148(3), 376 - 381. [doi].

Eberl F, Gardiner S, Campanile G, Surdon G, Venmans M and Prangnell P (2008) Ageformable panels for commercial aircraft. Proceedings of the Institution of Mechanical Engineers, Part G: Journal of Aerospace Engineering, 222(6), 873 - 886.

Ee KC, Dillon Jr OW and Jawahir IS (2005) Finite element modelling of residual stresses in machining induced by cutting using a tool with finite edge radius. International Journal of Mechanical Sciences, 47(10), 1161 - 1628.

El-Khabeery MM and Fattouh M (1989) Residual stress distribution caused by milling. International Journal of Machine Tools and Manufacture, 29(3), 391 - 401.

Foster AD, Mohamed MS, Lin J and Dean TA (2009) An investigation of lubrication and heat transfer for a sheet aluminium heat, form-quench (HFQ) process. Steel Research International, 79, 113 - 119.

Ho KC, J Lin and Dean TA (2004a) Modelling of springback in creep forming thick aluminium sheets. International Journal of Plasticity, 20(4-5), 733 - 751.

Ho KC, J Lin and Dean TA (2004b) Constitutive modelling of primary creep for age forming an aluminium alloy. Journal of Materials Processing Technology, 153-154, $122-127$.

Huang X, Sun J, Li J, Han X and Xiong Q (2013) An experimental investigation of residual stresses in high-speed end milling 7050-T7451 aluminium alloy. Advances in Mechanical Engineering, 2013, Article ID 592659, 7 pages [doi].

Islamoff II (1965) Metal-forming techniques. Washington DC, NASA Technology Utilization Division.

Kim HS and Koç M (2008) Numerical investigations on springback characteristics of aluminium sheet metal alloys in warm forming conditions. Journal of Materials Processing Technology, 204, 370 - 383. 
Koç M, Culp J and Altan T (2006) Prediction of residual stresses in quenched blocks and their reduction through cold working processes. Journal of Materials Processing Technology, 174(1-3), $342-354$.

Lam ACL, Chandaria V, Patel R, Simmonds J and Zou J (2011) Material characterisation and finite element modelling of rubber, PU, EVA and SALi as energy absorbing materials. MEng project report. Imperial College London.

Lam ACL and Lin J (2014) A validated analytical solution for the two-dimensional bending of aluminium plates under creep-ageing conditions. Key Engineering Materials, $622-$ $623,1107-1116$.

Lam ACL, Shi Z, Lin J, Huang X, Zeng Y and Dean TA (2015a) A method for designing lightweight and flexible creep-age forming tools using mechanical splines and sparse controlling points. International Journal of Advanced Manufacturing Technology. [doi].

Lam ACL, Shi Z, Huang X, Yang Y-L, Zeng Y and Lin J (2015b) Material modelling for creep-age forming of aluminium alloy 7B04. Proceedings of the $4^{\text {th }}$ International Conference on New Forming Technology, ICNFT 2015, 6-9 August 2015, Glasgow, UK.

Levers A (2003) Jumbo processes. Manufacturing Engineer, 82(3), 42 - 45.

Levers A (2008) Aircraft component manufacturing tool and method. Patent EP 1581357 B1. 26 March 2008.

Levers A (2010) Broughton: From Wellington Bombers to the A380. International Journal for the History of Engineering and Technology, 80(1), 55 - 79.

Lin J and Dean TA (2005) Modelling of microstructure evolution in hot forming using unified constitutive equations. Journal of Materials Processing Technology, 167(2-3), $354-362$.

Lin J, Ho KC and Dean TA (2006) An integrated process for modelling of precipitation hardening and springback in creep age-forming. International Journal of Machine Tools and Manufacture, 46(11), 1266 - 1270.

Munroe J, Wilkins K and Gruber M (2000) Integral Airframe Structures (IAS) - Validated feasibility study of integrally stiffened metallic fuselage panels for reducing 
manufacturing costs. Boeing Commercial Airplane Group, Seattle, Washington. Report number: NASA/CR-2000-209337.

Narasimhan $\mathbf{N}$ and Lovell $M$ (1999) Predicting springback in sheet metal forming: an explicit to implicit sequential solution procedure. Finite Element in Analysis and Design, 33, 29 - 42.

Prime MB and Hill MR (2002) Residual stress, stress relief, and inhomogeneity in aluminium plate. Scripta Materialia, 46(1), 77 - 82. [doi].

Rao B and Shin YC (2001) Analysis on high-speed face-milling of 7075-T6 aluminum using carbide and diamond cutters. International Journal of Machine Tools and Manufacture, 41(12), $1763-1787$.

Robinson JS, Tannder DA, van Petegem S and Evans A (2012) Influence of quenching and aging on residual stress in $\mathrm{Al}-\mathrm{Zn}-\mathrm{Mg}-\mathrm{Cu}$ alloy 7449. Material Science and Technology, 28(4), 420 - 430. [doi].

Tang ZT, Liu ZQ, Pan YZ, Wan Y and Ai X (2009) The influence of tool flank wear on residual stresses induced by milling aluminium alloy. Journal of Materials Processing Technology, 209(9), 4502 - 4508. [doi].

Ulutan D, Erdem Alaca B and Lazoglu I (2007) Analytical modelling of residual stresses in machining. Journal of Materials Processing Technology, 183(1), 77 - 87.

Wagoner RH and Li M (2007) Simulation of springback: Through-thickness integration. International Journal of Plasticity, 23, 345 - 360.

Wagoner RH, Lim H and Lee M-G (2013) Advanced issues in springback. International Journal of Plasticity, 45, 3 - 20.

Woodward M (2014) Introduction to the Pulstec $\mu$-X360 x-ray diffraction (XRD) based residual stress analyser and the $\operatorname{cosine} \alpha$ method of analysis. [Presentation] Imperial College London, $19^{\text {th }}$ November.

Yang H, Davies CM, Lin J and Dear JP (2013) Prediction and assessment of springback in typical creep age forming tools. Proceedings of the Institution of Mechanical Engineers, Part B: Journal of Engineering Manufacture, 227(9), 1340 - 1348. 
Young KA, Nervi S and Szabo B (2005) Machining-induced residual stress and distortion. SAE Technical Paper. [doi].

Zhan L, Lin J and Dean TA (2011a) A review of the development of creep age forming: Experimentation, modelling and applications. International Journal of Machine Tools \& Manufacture, 51, $1-17$.

Zhan L, Lin J, Dean TA and Huang M (2011b) Experimental studies and constitutive modelling of the hardening of aluminium alloy 7055 under creep age forming conditions. International Journal of Mechanical Sciences, 53(8), 595 - 605. 